\title{
INCERTEZA E ATIVIDADE ECONÔMICA NO BRASIL
}

\author{
Adonias Evaristo da Costa Filho*
}

\begin{abstract}
Resumo
Este artigo estuda a relação entre incerteza e atividade econômica no Brasil. A incerteza é aproximada por um índice baseado na frequência da palavra "incerteza" nas seções econômicas de jornais, pelo desvio-padrão das expectativas de crescimento econômico e pela volatilidade do mercado acionário. A incerteza é contra-cíclica, e choques de incerteza produzem efeitos negativos e rápidos na economia brasileira, quando comparados com choques na taxa de juros. Os resultados estão em linha com os encontrados para outros países.
\end{abstract}

Palavras-chave: Incerteza, Atividade.

\begin{abstract}
This paper is aimed at the relationship between uncertainty and economic activity in Brazil. Uncertainty is proxied by an index based on the frequency of economic uncertainty-related articles in newspapers, the standard deviation of growth expectations and stock market volatility. Uncertainty is countercyclical, and uncertainty shocks produce negative and quickier effects in Brazilian economy, when compared with interest rate shocks. The results are similar to those found for other countries.
\end{abstract}

Keywords: Uncertainty, Activity.

JEL classification: E00.

DOI: http ://dx.doi.org/10.1590/1413-8050/ea607

\footnotetext{
* Estudante de doutorado em Economia da UnB. E-mail: adoniasevaristo@hotmail.com
} 


\section{Introdução}

O objetivo deste artigo é analisar a relação entre medidas de incerteza e indicadores de atividade econômica no Brasil, em face da crescente pesquisa internacional sobre o tema, especialmente após o artigo de Bloom (2009).

Pesquisas econômicas recentes têm mostrado a importância dos efeitos negativos da incerteza para a atividade econômica. Para os Estados Unidos, associam a demora na recuperação da economia americana após a crise de 20072008 ao elevado nível de incerteza sobre a política econômica entre 2008 e 2011 (Baker et al. 2013).

No Brasil, tornou-se comum atribuir resultados econômicos negativos a partir de 2010, representados pelo aumento da inflação e redução do crescimento, ao aumento da incerteza, seja com origem nas políticas econômicas adotadas ou de origem externa. Apesar dos argumentos confluírem para uma relação negativa entre incerteza e atividade econômica, essa associação carece de suporte empírico, lacuna que esta pesquisa pretende suprir.

A incerteza se diferencia do risco por não poder ser definida estatisticamente, i.e., diante da incerteza, os agentes simplesmente não sabem o que vai acontecer - a distribuição de probabilidades é desconhecida —, ao passo que diante do risco as chances de diferentes resultados podem ser quantificadas, ou seja, a distribuição de probabilidades dos eventos é conhecida (GuerronQuintana 2012). Apesar desta distinção nos conceitos, muitas vezes se assume que a volatilidade (risco) é uma boa aproximação da incerteza. A pesquisa seminal de Bloom (2009) enfatizou a importância de se estudar os efeitos de choques nos segundos momentos (variâncias), em adição aos tradicionais choques nos primeiros momentos (médias).

Haddow et al. (2013) apresentam os possíveis canais de transmissão da incerteza para a atividade econômica. Do lado da demanda, choques de incerteza podem resultar em um aumento da poupança e redução do consumo, particularmente dos bens duráveis, mais sensíveis à confiança do consumidor. O investimento também pode ser afetado ou postergado em períodos de maior incerteza, ${ }^{1}$ assim como as decisões relativas à utilização da mão de obra por parte das firmas.

A influência negativa da incerteza no investimento no curto prazo, por sua vez, prejudica a formação de capital ao longo do tempo, e, portanto, a oferta agregada. Canais adicionais incluem o aumento do prêmio de risco e consequente queda dos preços dos ativos, e também a potencial redução do volume de crédito durante períodos de incerteza prolongada.

Para o Brasil, Silva Filho (2007) analisou os impactos da incerteza inflacionária no investimento. A incerteza inflacionária foi mensurada pelos erros de previsão fora da amostra a partir de modelos AR e passeio aleatório, utilizando dados de 1974 a 2002. O autor encontrou uma associação positiva entre a incerteza inflacionária e o nível da inflação, com base em testes de cointegração. Os resultados encontrados apontaram para uma alta significância das

\footnotetext{
${ }^{1}$ Bernanke (1983) apresenta justificativas teóricas para a relação negativa entre incerteza e o investimento: quando este é irreversível, os agentes preferem esperar para obter mais informações. Romer (1990) estendeu o mesmo argumento para o consumo, sugerindo que a volatilidade do mercado acionário na crise de 29 criou incerteza em relação à renda dos consumidores, levando a um maior consumo de bens não duráveis em comparação com duráveis. O teste básico efetuado foi regredir a taxa de crescimento da produção de um bem de consumo em suas defasagens, uma medida de produção total, a variabilidade do mercado acionário e variação do valor real das ações.
} 
medidas de incerteza inflacionária na acumulação de capital, representada pela utilização da capacidade instalada e pelos salários reais.

No Reino Unido, Denis \& Kannan (2013) usaram como proxy da incerteza a dispersão das expectativas de crescimento e uma medida de volatilidade do mercado acionário. Os autores encontraram que choques na incerteza provocam um efeito mais rápido na atividade econômica, vis-à-vis o de um choque monetário, reduzindo a atividade (representada pela produção industrial, PIB e desemprego) em um horizonte de 6 a 12 meses.

Bachmann et al. (2013) também utilizaram a dispersão das expectativas de crescimento tanto para a Alemanha quanto para os Estados Unidos como medida de incerteza, encontrando um efeito negativo entre o aumento da incerteza e a produção industrial de cada país.

Este artigo explora a relação entre 3 medidas de incerteza e um total de 6 indicadores de atividade econômica. As medidas de incerteza utilizadas foram: i) um índice construído com base na frequência da palavra "incerteza" nas seções de economia de alguns jornais, ii) a variabilidade das expectativas de crescimento econômico e iii) a variabilidade do mercado acionário brasileiro. Por sua vez, foram utilizados os seguintes indicadores de atividade econômica: produção industrial, vendas a varejo, confiança do consumidor, estoque de empregados formais do CAGED, taxa de desemprego e o índice IBC-BR do Banco Central.

Além da relação entre choques de incerteza e atividade econômica, a pesquisa explora os efeitos desses choques no contexto da política monetária, contrapondo os efeitos de choques de incerteza e na taxa de juros.

O trabalho prossegue da seguinte forma. A seção 2 detalha as medidas de incerteza utilizadas. A seção 3 apresenta a metodologia, e a seção 4, os dados utilizados. A seção 5 mostra os resultados para cada medida de incerteza, enquanto a seção 6 prossegue com a comparação entre choques de incerteza e choques na taxa de juros. A seção 7 conclui. $O$ apêndice apresenta o índice construído e os testes de raiz unitária efetuados.

\section{Medidas de incerteza}

Esta seção apresenta as três medidas de incerteza utilizadas. Todas encontram respaldo na literatura pertinente aos efeitos reais de choques de incerteza.

\section{1 Índice com base na frequência da palavra "incerteza" nas seções de economia de jornais}

A primeira medida tomou como base a frequência com que a palavra "incerteza" apareceu nas seções de economia dos jornais O Estado de São Paulo, Zero Hora, Estado de Minas e Correio Braziliense entre 2004 e 2013. Esse índice foi construído inspirado em Alexopoulos \& Cohen (2009), que construíram um índice semelhante para a economia americana, baseado na frequência da palavra incerteza e atividade econômica no New York Times. Conforme enfatizado pelos autores, a frequência da palavra "incerteza" pode refletir o grau de incerteza médio sentido por consumidores e produtores na economia. Períodos de maior incerteza tendem a ser acompanhados por matérias sobre os fatos geradores de incerteza, repercutindo a incerteza diante da população. Baker et al. (2013) também se baseiam na frequência de palavras relacionadas à in- 
certeza para construírem um índice de incerteza de política econômica para os Estados Unidos.

Para o Brasil, o índice foi construído utilizando a busca pela palavra "incerteza" no Clipping de Notícias da Radiobrás. ${ }^{2}$ Na época da consulta, os jornais mencionados estavam disponíveis. Optou-se por desconsiderar a base de dados da Gazeta Mercantil, tendo em vista sua descontinuidade em 2009. Somou-se a frequência absoluta da palavra incerteza de cada jornal em um determinado mês para se chegar a um número acumulado. Em seguida, construiuse um índice normalizado, subtraindo-se a média e dividindo-se pelo desviopadrão. A figura 1 apresenta o índice construído, os dados estão apresentados no apêndice, e a base de dados está prontamente disponível com o autor.

\subsection{Desvio-padrão das expectativas de crescimento econômico}

A segunda medida de incerteza considerada foi o desvio-padrão das expectativas de crescimento econômico. Bloom (2014) argumenta que períodos de maior dispersão das expectativas dos agentes refletem maior incerteza, apresentando evidências de que o desvio-padrão das expectativas de crescimento aumenta durante períodos de recessão nos Estados Unidos. Bachmann et al. (2013) encontram suporte para medidas de incerteza baseadas na dispersão das expectativas dos agentes, baseados em uma elevada correlação entre medidas de dispersão ex-ante e erros de previsão ex-post dos agentes, justificando assim o emprego da variabilidade das expectativas dos agentes como uma medida de incerteza.

Seguindo essa linha, utilizamos o desvio-padrão das expectativas do mercado em relação ao crescimento econômico para 1,2 e 3 anos à frente, cuja fonte é a pesquisa Focus do Banco Central. Como as séries de expectativas têm frequência diária, utilizou-se a média das expectativas em um determinado mês para um determinado ano para encontrar o valor na frequência mensal. Com base nesses dados, foram criadas séries do desvio-padrão das expectativas do mercado para 1, 2, e 3 anos à frente. Foram calculadas séries de prazo fixo, evitando o encurtamento da série à razão de 1/12 avos após transcorrido um determinado mês. Aplicou-se metodologia semelhante à empregada em Minella et al. (2003), consistindo basicamente em uma ponderação entre as expectativas do ano corrente e do próximo ano. A fórmula utilizada foi a seguinte:

$$
d p_{i+1, j}=\frac{\left(12-m \hat{e} s_{j}\right)}{12} *\left(d p_{i}\right)+\frac{m \hat{e} s_{j}}{12} * d p_{i+1}
$$

onde $i+1$ se refere ao ano de prazo fixo para o qual a série de expectativa foi construída, onde $i=0,1,2$ e $j=1, \ldots, 12$ se refere ao mês em questão. À medida que o ano se aproxima do seu fim, o peso das expectativas para o ano subsequente passa a ser crescente. ${ }^{3}$

\footnotetext{
${ }^{2}$ Agradeço a empresa EBC, que prontamente disponibilizou uma senha de acesso ao sistema, permitindo a consulta à base de dados em janeiro de 2014.

${ }^{3}$ Para exemplificar a metodologia utilizada, no final de 2013 estavam disponíveis dados para o desvio-padrão das expectativas de crescimento para 2013, 2014, 2015, 2016 e 2017, correspondendo a $j=0,1,2,3,4$, respectivamente. Pela fórmula acima, a expectativa para 2013 equivale a $i=0$ e para 2014 a $i=1$. Em novembro de 2013, o desvio-padrão das expectativas de crescimento para 1 ano à frente era composto de uma ponderação em que o peso para 2013 era de $1 / 12$, enquanto o peso para 2014 era de 11/12. Em dezembro de 2013, a expectativa para 1 ano
} 
O objetivo dessa metodologia foi evitar saltos nas séries de expectativas em função da passagem de um ano para o outro, o que tende a afetar as expectativas para um prazo mais curto em relação às de prazo mais longo. Os gráficos das séries construídas de desvio-padrão das expectativas de crescimento para 1,2 e 3 anos à frente estão apresentados na Figura 1.

\subsection{Variabilidade do mercado acionário}

A terceira medida de incerteza utilizada foi a padrão na literatura sobre choques de incerteza, a variabilidade do mercado acionário. A identificação de períodos de maior incerteza com a variabilidade do mercado de ações tem precedentes, por exemplo, no estudo de Bloom (2009), além de Denis \& Kannan (2013), Bachmann et al. (2013), Romer (1990). Conforme apontado por Haddow et al. (2013), na medida em que os preços das ações refletem perspectivas sobre a demanda das empresas, a volatilidade do mercado de ações pode ser uma boa proxy da incerteza.

Embora o tamanho do mercado acionário brasileiro seja bastante inferior ao do americano, ${ }^{4}$ a variabilidade do mercado acionário pode indicar períodos de maior incerteza na economia. ${ }^{5}$ Nesse sentido, Alexopoulos \& Cohen (2009) argumentam que mesmo que os indivíduos não participem do mercado acionário, eles podem tomar o mercado acionário como um sinal do estado da economia.

A série de volatilidade do IBOVESPA utilizada neste trabalho foi retirada do IPEADATA. Como a série é calculada com base nas taxas diárias de retorno entre as cotações de fechamento observadas nos últimos 21 dias de negociação, utilizou-se para um determinado mês o valor da série para o último dia útil daquele mês, de forma que refletisse a variabilidade do mercado acionário brasileiro ao longo do mês.

Assim como as demais medidas de incerteza utilizadas, a série da volatilidade do IBOVESPA é apresentada na Figura 1. O período entre setembro de 2008 e abril de 2009 se destaca, no auge da crise internacional. Entretanto, outros períodos também se destacam, mostrados na Tabela $1,{ }^{6}$ e foram identificados por meio da leitura de jornais da época.

Dos eventos listados acima, nota-se uma grande importância de fatores externos de incerteza, em comparação com fatores domésticos. Destes, destaque para a mudança do regime cambial em 1999, eleições de 2002 e a mini crise política de 2004, envolvendo um assessor do então Ministro da Casa Civil José Dirceu.

\footnotetext{
à frente equivalia à expectativa para 2014. Em janeiro de 2014, o desvio-padrão nas expectativas de crescimento passou a ser composto pela expectativa para 2014 e 2015 . Nesse sentido, a série do desvio-padrão das expectativas para 1 ano à frente é sempre calculada com $i=0$ e $i=1$,para 2 anos à frente com $i=1$ e $i=2$, e para 3 anos à frente com $i=2$ e $i=3$. Não foi construída uma série de prazo fixo para 4 anos à frente porque nem sempre a série para o 40 ano à frente está imediamente disponível nas viradas dos anos. Por exemplo, a série para 2016 só se tornou disponível em julho de 2012, e a série para 2018 só se tornou disponível em fevereiro de 2014.

${ }^{4}$ Dados do Banco Mundial para o final de 2012 mostram que o valor de mercado das empresas listadas em bolsa nos EUA era de $114 \%$ e $54 \%$ para o Brasil. Link: http://wdi.worldbank.org/table/5.4 Acesso em 17 de junho de 2014.

${ }^{5}$ Agradeço ao parecerista por ressaltar este ponto.

${ }^{6}$ Para efeito de comparação, a tabela A.4 no apêndice apresenta os períodos de maior incerteza pelo índice.
} 
Tabela 1: Períodos de maior incerteza pela volatilidade do mercado acionário

\begin{tabular}{ll}
\hline Período & Eventos \\
\hline fev/99 & Mudança do regime cambial \\
abr/00 & Grande queda do NASDAQ, estouro da bolha ponto.com \\
set/01 & Atentados terroristas \\
out/02 & Eleições de 2002 \\
fev/04 & Crise política (rumores de saída de José Dirceu da Casa Civil, caso envolvendo \\
& Waldomiro Diniz \\
mar/05 & Alta de juros nos EUA, e preocupações com o aumento da inflação americana \\
jun/06 & Alta de juros nos EUA, e preocupações com o aumento da inflação americana \\
jan/08 & Preocupações com os efeitos recessivos da crise do subprime \\
ago/11 & Rebaixamento da nota de crédito dos EUA \\
jul/12 & Crise da Zona do Euro (possibilidade da Grécia sair da Zona do Euro) \\
\hline
\end{tabular}
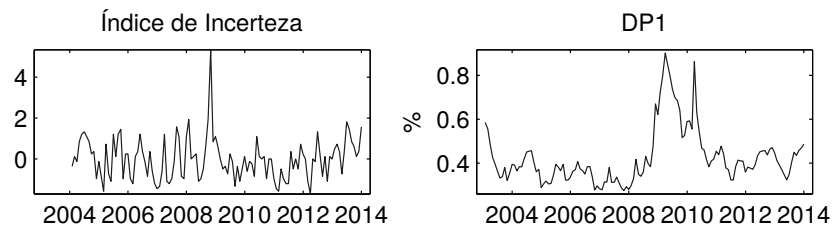

DP2 DP3
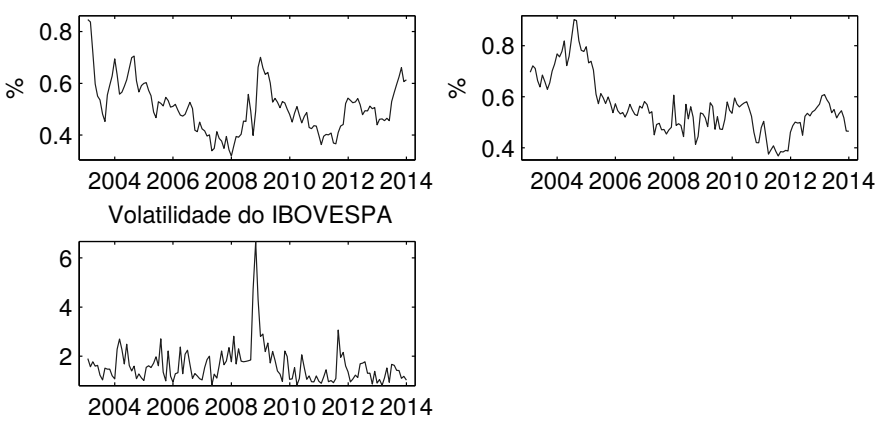

Obs.: Medidas de incerteza utilizadas: i) índice de incerteza, construído a partir da frequência da palavra incerteza nas seções econômicas de jornais, ii) DP1:

desvio-padrão das expectativas de crescimento econômico 1 ano à frente, ii) DP2: desvio-padrão das expectativas de crescimento 2 anos à frente, iii) DP3: desvio-padrão das expectativas de crescimento 3 anos à frente, iv) volatilidade do IBOVESPA.

Figura 1: Medidas de incerteza 


\section{Metodologia}

A metodologia consistiu na estimação de vetores autorregressivos (VARs) bivariados, em consonância com os demais estudos da literatura pertinente (Bloom 2009, Denis \& Kannan 2013, Bachmann et al. 2013, dentre outros). Foram estimados diversos VARs entre as medidas de incerteza (índice de incerteza, desvio-padrão das expectativas de crescimento e volatilidade do mercado acionário) e os indicadores de atividade econômica, utilizando para este fim o índice de atividade econômica do Banco Central IBC-BR, tido como uma prévia do PIB, uma série de confiança do consumidor, a produção industrial, taxa de desemprego, vendas a varejo e estoque de empregados formais pelo CAGED.

Os modelos VAR foram estimados adotando-se a decomposição de Choleski para a matriz de variância e covariância, resultando em uma estrutura recursiva, segundo a qual a primeira variável do VAR é afetada contemporaneamente somente pelo seu próprio choque e a segunda variável é afetada contemporaneamente por choques na primeira variável e por um choque em si mesma. Nos modelos em questão, seguindo a literatura mencionada, a variável relacionada à incerteza foi ordenada em primeiro, e a variável associada à atividade econômica foi ordenada em segundo. Assim, a incerteza é impactada apenas por um choque em si mesma. Outro argumento para a ordenação utilizada foi que, conforme mostrado acima, ao menos para a volatilidade do mercado acionário, os choques de incerteza de maior magnitude têm origem mais frequente em fatores externos, corroborando a opção da ordenação da incerteza em primeiro lugar.

A seleção dos critérios das defasagens dos VARs estimados foi feita por meio dos critérios de Scharwz, Hannan-Quinn e Akaike. Quando o VAR na defasagem indicada pelos critérios continuava apresentando auto-correlação serial, foram adicionadas defasagens adicionais.

\section{Descrição dos dados}

Segue uma descrição das séries utilizadas nas estimações. Para a taxa de desemprego a série utilizada foi a diferença entre a série dessazonalizada e o seu filtro HP. Para as demais aplicou-se o filtro HP ao logaritmo da série original, utilizando lambda igual a 129.600, recomendado para séries na frequência mensal, e em seguida subtraiu-se a série filtrada do log da série original. Assim, nas estimações foi utilizada a diferença entre o logaritmo da série original e o filtro HP aplicado ao logaritmo da série. ${ }^{7}$ As séries foram então multiplicadas por 100, de forma a já deixá-las em percentual. A figura 2 apresenta as séries, e o apêndice mostra os testes de raiz unitária empregados.

- Índice de atividade econômica do Banco Central (IBC-BR), série já dessazonalizada. Retirado do IPEADATA.

- Índice de Confiança do Consumidor da Federação do Comércio do Estado de São Paulo (fonte:Fecomércio SP). Retirado do IPEADATA.

- Taxa de Desemprego das regiões metropolitanas (fonte: IBGE). Retirado do IPEADATA e dessazonalizada pelo método X-12 ARIMA.

\footnotetext{
${ }^{7}$ Procedimento em linha com o adotado em Bloom (2009), que praticamente deu origem a esta vertente de pesquisa.
} 
- Produção industrial (fonte: IBGE), série já dessazonalizada. Retirada do IPEADATA.

- Vendas a varejo (fonte: IBGE), série já dessazonalizada. Retirada do IPEADATA.

- Estoque de empregados formais do CAGED (fonte: Ministério do Trabalho e Emprego), dessazonalizada pelo método X-12 ARIMA.

- Volatilidade do índice IBOVESPA. Retirada do IPEADATA.

- Variação cambial mensal da taxa de câmbio BRL/USD. Construída a partir da série de taxa de câmbio comercial média mensal do IPEADATA.

O período das séries e das estimações vai de janeiro de 2003 a dezembro de 2013, contendo 132 observações. Quando os VARs foram estimados com o índice de incerteza, o período vai de janeiro e 2004 a dezembro de 2013, com 120 observações. Isso foi necessário, pois a base de dados utilizada para construir o índice não retroage mais do que 10 anos.
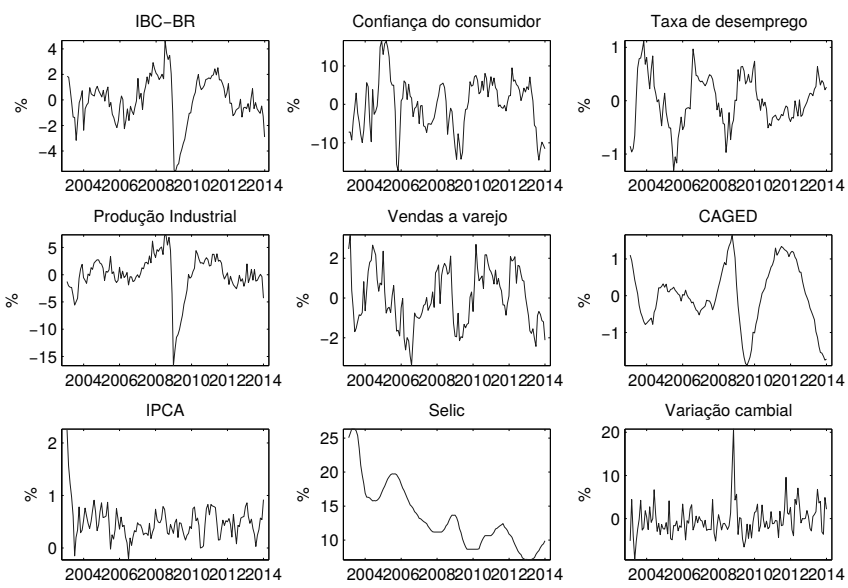

Figura 2: Séries utilizadas nas estimações

Tabela 2: Coeficientes de correlação contemporânea entre incerteza e medidas de atividade econômica

\begin{tabular}{llccccr}
\hline $\begin{array}{l}\text { Medida de } \\
\text { Incerteza }\end{array}$ & IBC-BR & Confiança & Desemprego & $\begin{array}{l}\text { Produção } \\
\text { Industrial }\end{array}$ & $\begin{array}{c}\text { Vendas a } \\
\text { varejo }\end{array}$ & CAGED \\
\hline Desvio-padrão 1 & $-0,48$ & $-0,24$ & 0,15 & $-0,55$ & $-0,08$ & $-0,31$ \\
Desvio-padrão 2 & $-0,41$ & $-0,26$ & 0,03 & $-0,45$ & $-0,01$ & $-0,22$ \\
Desvio-padrão 3 & $-0,1$ & 0,13 & 0,12 & $-0,06$ & 0,14 & $-0,23$ \\
Indice & $-0,07$ & $-0,24$ & $-0,02$ & 0 & $-0,02$ & $-0,04$ \\
Volatilidade & $-0,01$ & $-0,16$ & $-0,07$ & $-0,05$ & 0 & 0,17 \\
\hline
\end{tabular}

A análise da correlação contemporânea entre as medidas de incerteza consideradas e os indicadores de atividade econômica mostra que a incerteza é contra-cíclica, resultado em linha com o encontrado para outros países (Bloom 
2009). As maiores magnitudes envolvem a incerteza mensurada pelo desviopadrão das expectativas de crescimento econômico e a atividade medida pelo IBC-BR e pela produção industrial, com correlações negativas entre 0,4 e 0,5.

$O$ índice de incerteza é mais relacionado com a confiança do consumidor, possivelmente refletindo o fato de ter sido construído a partir dos jornais, com a frequência de matérias relacionadas à incerteza diminuindo a confiança do consumidor. A volatilidade do mercado acionário não apresenta grande correlação contemporânea com as medidas de atividade.

\section{Resultados}

Nesta seção apresentamos os resultados encontrados para cada medida de incerteza utilizada.

\section{1 Índice de incerteza}

Para o índice de incerteza, construído com base na frequência da palavra "incerteza" nas seções de economia de alguns jornais, as funções de resposta ao impulso dos modelos VAR mostram um efeito negativo na atividade econômica, apresentadas na figura 3. A produção industrial recua mais de $1 \%$ abaixo da tendência após um choque de incerteza. A segunda variável mais afetada é a confiança do consumidor, que também recua cerca de $1 \%$ após o choque. O IBC-BR, vendas a varejo e CAGED têm uma resposta mais modesta, mas também declinam. Por sua vez, o desemprego se eleva em pequena magnitude.

As funções de impulso resposta mostram que os efeitos de um choque de incerteza são sentidos em prazo inferior a 5 meses após a incidência do choque. Os efeitos mais profundos são sentidos na confiança do consumidor e na produção industrial.

A decomposição da variância dos modelos estimados, apresentada na tabela 3, mostra que as variáveis mais explicadas pelo índice de incerteza são o IBC-BR e a produção industrial. No horizonte de 10 meses, cerca de $30 \%$ da variação destas séries é explicada pelo índice de incerteza. O emprego, medido pelo CAGED, demora um pouco para responder, mas após 10 meses também é bastante afetado pela incerteza, com o percentual da variância explicado pelo índice superando $20 \%$.

\subsection{Desvio-padrão das expectativas de crescimento econômico}

O efeito de choques na medida de incerteza baseada no desvio-padrão das expectativas de crescimento para 1 ano à frente é apresentado na figura 4 . A variável mais afetada após um choque na variância das expectativas é a confiança do consumidor, que chega a recuar cerca de $1 \%$ abaixo da tendência. Em segundo lugar vem a produção industrial, que cai cerca de $0,5 \%$ abaixo da tendência. A resposta do IBC-BR, vendas a varejo e CAGED é bem mais sutil, recuando entre $-0,2$ e $-0,3 \%$ abaixo da tendência. A taxa de desemprego aumenta, porém, o efeito quantitativo é pequeno, inferior a 0,05\%. Em geral, os intervalos de confiança para os modelos estimados são maiores do que os obtidos utilizando o índice de incerteza.

A decomposição da variância dos modelos estimados, apresentada na tabela 5, mostra que novamente o IBC-BR e a produção industrial são as variá- 

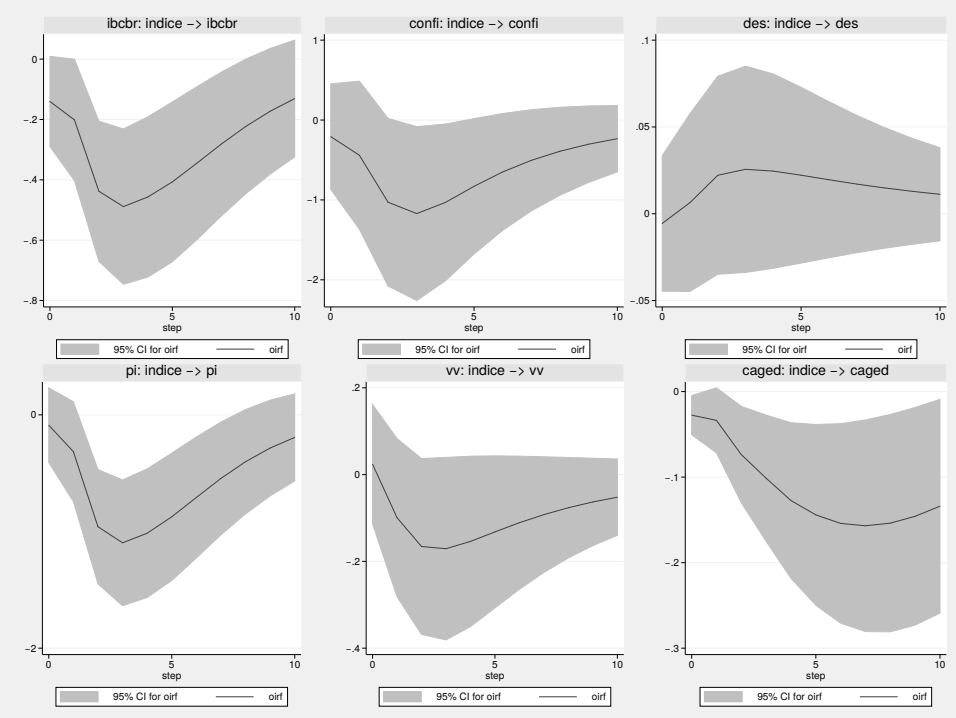

Obs.: Em cima, da esquerda para a direita: resposta do IBC-BR, confiança do consumidor e taxa de desemprego a um choque do índice de incerteza. Embaixo, da esquerda para a direita: resposta da produção industrial, vendas a varejo e CAGED a um choque de incerteza. Eixo vertical em \% da tendência.

Figura 3: Funções de resposta ao impulso dos VARs estimados. Medida de incerteza: índice

Tabela 3: Decomposição da variância dos VARs estimados. Medida de incerteza: índice

\begin{tabular}{lcccccc}
\hline $\begin{array}{l}\text { Horizonte } \\
\text { (meses) }\end{array}$ & IBC-BR & Confiança & Desemprego & $\begin{array}{c}\text { Produção } \\
\text { Industrial }\end{array}$ & $\begin{array}{c}\text { Vendas a } \\
\text { varejo }\end{array}$ & CAGED \\
\hline 1 & $3 \%$ & $0 \%$ & $0 \%$ & $0 \%$ & $0 \%$ & $5 \%$ \\
2 & $5 \%$ & $1 \%$ & $0 \%$ & $2 \%$ & $1 \%$ & $4 \%$ \\
3 & $13 \%$ & $4 \%$ & $1 \%$ & $12 \%$ & $3 \%$ & $7 \%$ \\
4 & $20 \%$ & $6 \%$ & $1 \%$ & $21 \%$ & $4 \%$ & $10 \%$ \\
5 & $24 \%$ & $8 \%$ & $1 \%$ & $26 \%$ & $5 \%$ & $13 \%$ \\
6 & $27 \%$ & $9 \%$ & $2 \%$ & $29 \%$ & $6 \%$ & $15 \%$ \\
7 & $29 \%$ & $10 \%$ & $2 \%$ & $31 \%$ & $6 \%$ & $17 \%$ \\
8 & $30 \%$ & $10 \%$ & $2 \%$ & $32 \%$ & $6 \%$ & $19 \%$ \\
9 & $31 \%$ & $10 \%$ & $2 \%$ & $33 \%$ & $7 \%$ & $21 \%$ \\
10 & $31 \%$ & $10 \%$ & $2 \%$ & $33 \%$ & $7 \%$ & $22 \%$ \\
\hline
\end{tabular}

Obs. Percentual da variância da variável em consideração explicada pelo índice de incerteza no VAR bivariado. 
Tabela 4: Testes de auto-correlação serial nos modelos VAR estimados. Medida de incerteza: índice

\begin{tabular}{lccc}
\hline Variável do VAR (além da incerteza) & Defasagens do VAR & Chi2 & P-valor \\
\hline IBC-BR & 2 & 10,665 & 0,89 \\
Confiança do Consumidor & 2 & 0,6690 & 0,95 \\
Taxa de Desemprego & 2 & 30,098 & 0,55 \\
Produção Industrial & 2 & 0,6496 & 0,95 \\
Vendas a Varejo & 2 & 46,153 & 0,32 \\
CAGED & 3 & 76,140 & 0,10 \\
\hline
\end{tabular}

Obs. O teste apresentado é o de multiplicadores de Lagrange, cuja hipótese nula é ausência de auto-correlação serial na respectiva defasagem. O p-valor se refere à última defasagem do VAR.

veis mais explicadas pela variabilidade das expectativas de crescimento econômico, com o percentual oscilando entre 10 e $15 \%$.

Tabela 5: Decomposição da variância dos VARs estimados. Medida de incerteza: desvio-padrão das expectativas de crescimento 1 ano à frente

\begin{tabular}{lcccccc}
\hline $\begin{array}{l}\text { Horizonte } \\
\text { (meses) }\end{array}$ & IBC-BR & Confiança & Desemprego & $\begin{array}{c}\text { Produção } \\
\text { Industrial }\end{array}$ & $\begin{array}{c}\text { Vendas a } \\
\text { varejo }\end{array}$ & CAGED \\
\hline 1 & $1 \%$ & $2 \%$ & $1 \%$ & $0 \%$ & $3 \%$ & $0 \%$ \\
2 & $4 \%$ & $6 \%$ & $1 \%$ & $6 \%$ & $3 \%$ & $1 \%$ \\
3 & $6 \%$ & $7 \%$ & $1 \%$ & $9 \%$ & $4 \%$ & $2 \%$ \\
4 & $8 \%$ & $7 \%$ & $1 \%$ & $11 \%$ & $4 \%$ & $3 \%$ \\
5 & $9 \%$ & $7 \%$ & $1 \%$ & $12 \%$ & $4 \%$ & $3 \%$ \\
6 & $10 \%$ & $7 \%$ & $1 \%$ & $13 \%$ & $5 \%$ & $4 \%$ \\
7 & $11 \%$ & $7 \%$ & $2 \%$ & $14 \%$ & $5 \%$ & $5 \%$ \\
8 & $11 \%$ & $7 \%$ & $2 \%$ & $15 \%$ & $5 \%$ & $5 \%$ \\
9 & $12 \%$ & $7 \%$ & $3 \%$ & $15 \%$ & $6 \%$ & $5 \%$ \\
10 & $13 \%$ & $7 \%$ & $3 \%$ & $15 \%$ & $6 \%$ & $6 \%$ \\
\hline
\end{tabular}

Obs. Percentual da variância da variável em consideração explicada pela medida de incerteza no VAR bivariado.

Tabela 6: Testes de auto-correlação serial nos modelos VAR estimados. Medida de incerteza: desvio-padrão das expectativas de crescimento 1 ano à frente

\begin{tabular}{lccc}
\hline Variável do VAR (além da incerteza) & Defasagens do VAR & Chi2 & P-valor \\
\hline IBC-BR & 2 & 4,54 & 0,33 \\
Confiança do Consumidor & 2 & 1,86 & 0,76 \\
Taxa de Desemprego & 2 & 1,30 & 0,86 \\
Produção Industrial & 2 & 1,12 & 0,88 \\
Vendas a Varejo & 2 & 5,86 & 0,20 \\
CAGED & 3 & 6,03 & 0,19 \\
\hline
\end{tabular}

Obs. O teste apresentado é o de multiplicadores de Lagrange, cuja hipótese nula nula é ausência de auto-correlação serial na respectiva defasagem. $\mathrm{O}$ p-valor se refere à última defasagem do VAR.

Para o desvio-padrão das expectativas de crescimento 2 anos à frente, os efeitos são semelhantes aos obtidos com a série de prazo mais curto. Após um choque de incerteza a confiança do consumidor é a variável que é mais afetada, caindo cerca de $1 \%$ abaixo da tendência. O efeito na produção industrial os- 


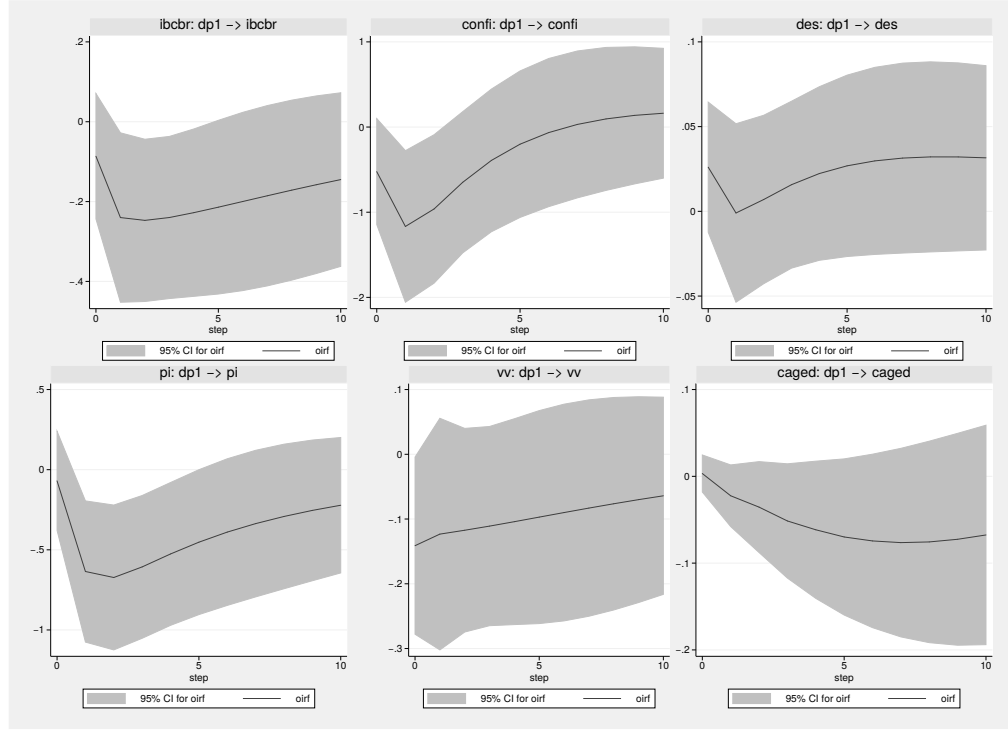

Obs.: Em cima, da esquerda para a direita: resposta do IBC-BR, confiança do consumidor e taxa de desemprego a um choque no desvio-padrão das expectativas de crescimento para 1 ano à frente. Embaixo, da esquerda para a direita: resposta da produção industrial, vendas a varejo e CAGED a um choque de incerteza. Eixo vertical em \% da tendência.

Figura 4: Funções de resposta ao impulso dos VARs estimados. Medida de incerteza: desvio-padrão das expectativas de crescimento 1 ano à frente

cila entre $-0,5 \%$ e $-1 \%$. Novamente, o efeito no IBC-BR e nas vendas a varejo é de menor magnitude, caindo entre 0,4 e $0,2 \%$, respectivamente. As variáveis relacionadas ao mercado de trabalho apresentam uma resposta quantitativamente pequena, com a taxa de desemprego se elevando menos do que $0,05 \%$, e o estoque de empregados formais do CAGED declinando $0,1 \%$.

A decomposição da variância dos VARs estimados com essa medida de incerteza, mostrada na tabela 7 , novamente aponta para a produção industrial e IBC-BR como as séries cujas variâncias são mais explicadas pela incerteza em relação ao crescimento econômico no futuro.

Curiosamente, os resultados para as expectativas de crescimento para 3 anos à frente não indicam um efeito muito grande na atividade econômica. O efeito base de maior relevância ocorre novamente na confiança do consumidor e na produção industrial, com esta recuando um pouco menos do que $-0,5 \%$. O efeito base no IBC-BR é de queda de $0,2 \%$. A taxa de desemprego se eleva em menos do que $0,05 \%$, enquanto o emprego se mantém praticamente constante. Os intervalos de confiança são mais largos do que os obtidos anteriormente. As funções de resposta ao impulso estão apresentadas na figura 6.

A decomposição da variância dos modelos estimados, na tabela 9, mostra um efeito menor do que o obtido anteriormente, com a taxa de desemprego sendo a variável mais afetada pela incerteza, com esta respondendo por cerca de $6 \%$ daquela após 10 meses. 


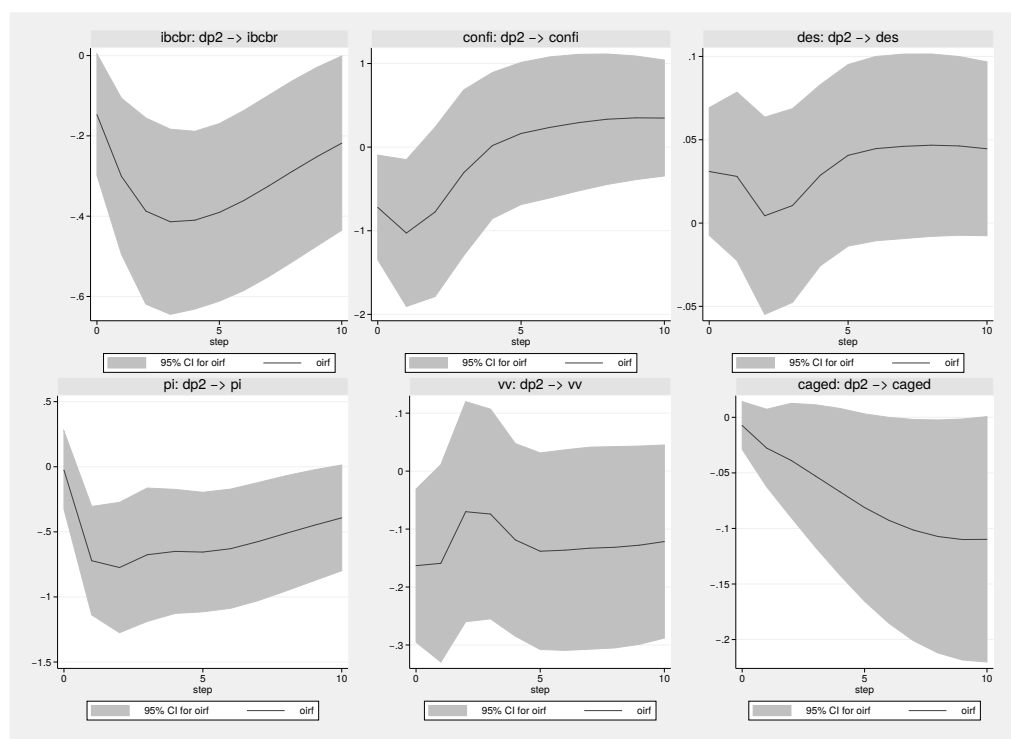

Obs.: Em cima, da esquerda para a direita: resposta do IBC-BR, confiança do consumidor e taxa de desemprego a um choque no desvio-padrão das expectativas de crescimento para 2 anos à frente. Embaixo, da esquerda para a direita: resposta da produção industrial, vendas a varejo e CAGED a um choque de incerteza. Eixo vertical em \% da tendência.

Figura 5: Funções de resposta ao impulso dos VARs estimados. Medida de incerteza: desvio-padrão das expectativas de crescimento 2 anos à frente

Tabela 7: Decomposição da variância dos VARs estimados. Medida de incerteza: desvio-padrão das expectativas de crescimento 2 anos à frente.

\begin{tabular}{lcccccc}
\hline $\begin{array}{l}\text { Horizonte } \\
\text { (meses) }\end{array}$ & IBC-BR & Confiança & Desemprego & $\begin{array}{c}\text { Produção } \\
\text { Industrial }\end{array}$ & $\begin{array}{c}\text { Vendas a } \\
\text { varejo }\end{array}$ & CAGED \\
\hline 1 & $3 \%$ & $4 \%$ & $2 \%$ & $0 \%$ & $4 \%$ & $0 \%$ \\
2 & $8 \%$ & $6 \%$ & $2 \%$ & $8 \%$ & $5 \%$ & $2 \%$ \\
3 & $14 \%$ & $6 \%$ & $1 \%$ & $13 \%$ & $4 \%$ & $3 \%$ \\
4 & $19 \%$ & $6 \%$ & $1 \%$ & $15 \%$ & $4 \%$ & $3 \%$ \\
5 & $23 \%$ & $5 \%$ & $2 \%$ & $17 \%$ & $5 \%$ & $4 \%$ \\
6 & $27 \%$ & $5 \%$ & $3 \%$ & $20 \%$ & $6 \%$ & $5 \%$ \\
7 & $30 \%$ & $5 \%$ & $4 \%$ & $22 \%$ & $6 \%$ & $7 \%$ \\
8 & $32 \%$ & $5 \%$ & $5 \%$ & $24 \%$ & $7 \%$ & $8 \%$ \\
9 & $34 \%$ & $5 \%$ & $6 \%$ & $26 \%$ & $8 \%$ & $9 \%$ \\
10 & $35 \%$ & $6 \%$ & $7 \%$ & $27 \%$ & $9 \%$ & $11 \%$ \\
\hline
\end{tabular}

Obs. Percentual da variância da variável em consideração explicada pela medida de incerteza no VAR bivariado. 


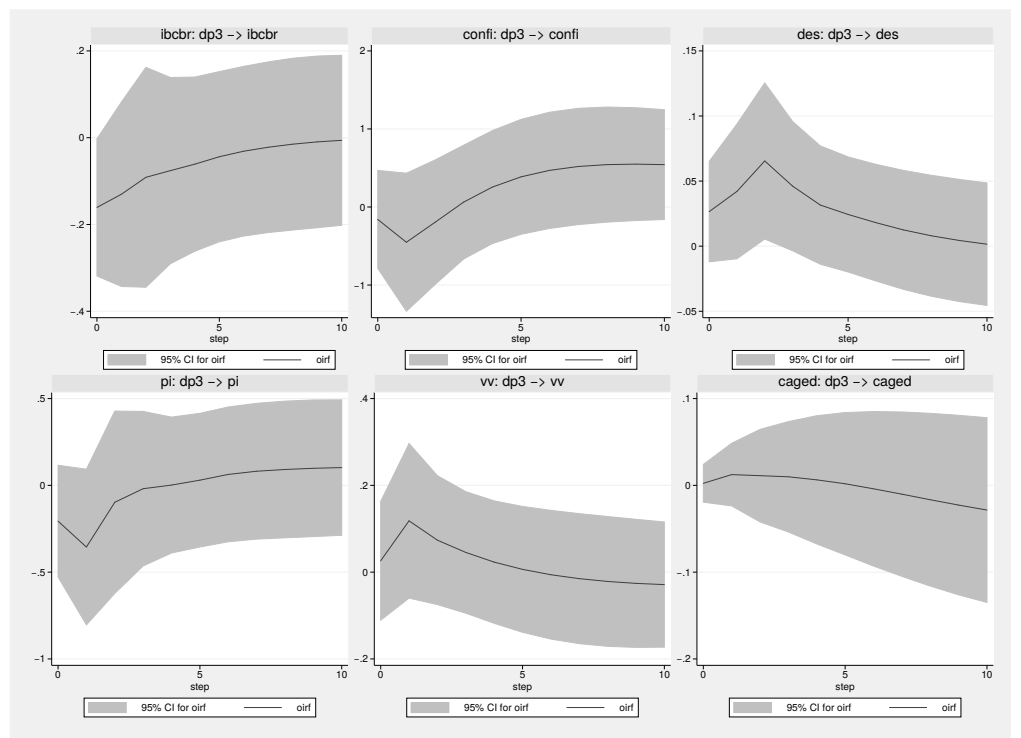

Obs.: Em cima, da esquerda para a direita: resposta do IBC-BR, confiança do consumidor e produção industrial a um choque no desvio-padrão das expectativas de crescimento 3 anos à frente. Embaixo, da esquerda para a direita: resposta da produção industrial, vendas a varejo e CAGED a um choque de incerteza. Eixo vertical em \% da tendência.

Figura 6: Funções de resposta ao impulso dos VARs estimados. Medida de incerteza: desvio-padrão das expectativas de crescimento 3 anos à frente

Tabela 8: Testes de auto-correlação serial nos modelos VAR estimados. Medida de incerteza: desvio-padrão das expectativas de crescimento 2 anos à frente.

\begin{tabular}{lccc}
\hline Variável do VAR (além da incerteza) & Defasagens do VAR & Chi2 & P-valor \\
\hline IBC-BR & 3 & 3,38 & 0,49 \\
Confiança do Consumidor & 3 & 4,47 & 0,34 \\
Taxa de Desemprego & 3 & 5,76 & 0,21 \\
Produção Industrial & 3 & 4,79 & 0,30 \\
Vendas a Varejo & 3 & 2,92 & 0,57 \\
CAGED & 3 & 5,01 & 0,28 \\
\hline
\end{tabular}

Obs. O teste apresentado é o de multiplicadores de Lagrange, cuja hipótese nula nula é ausência de auto-correlação serial na respectiva defasagem. O p-valor se refere à última defasagem do VAR. 
Tabela 9: Decomposição da variância dos VARs estimados. Medida de incerteza: desvio-padrão das expectativas de crescimento 3 anos à frente.

\begin{tabular}{lcccccc}
\hline $\begin{array}{l}\text { Horizonte } \\
\text { (meses) }\end{array}$ & IBC-BR & Confiança & Desemprego & $\begin{array}{c}\text { Produção } \\
\text { Industrial }\end{array}$ & $\begin{array}{c}\text { Vendas a } \\
\text { varejo }\end{array}$ & CAGED \\
\hline 1 & $3 \%$ & $0 \%$ & $1 \%$ & $1 \%$ & $0 \%$ & $0 \%$ \\
2 & $3 \%$ & $1 \%$ & $3 \%$ & $2 \%$ & $1 \%$ & $0 \%$ \\
3 & $2 \%$ & $1 \%$ & $5 \%$ & $2 \%$ & $1 \%$ & $0 \%$ \\
4 & $2 \%$ & $1 \%$ & $6 \%$ & $2 \%$ & $1 \%$ & $0 \%$ \\
5 & $2 \%$ & $1 \%$ & $6 \%$ & $1 \%$ & $1 \%$ & $0 \%$ \\
6 & $2 \%$ & $1 \%$ & $6 \%$ & $1 \%$ & $1 \%$ & $0 \%$ \\
7 & $2 \%$ & $2 \%$ & $6 \%$ & $1 \%$ & $1 \%$ & $0 \%$ \\
8 & $2 \%$ & $2 \%$ & $6 \%$ & $1 \%$ & $1 \%$ & $0 \%$ \\
9 & $2 \%$ & $3 \%$ & $6 \%$ & $1 \%$ & $1 \%$ & $0 \%$ \\
10 & $2 \%$ & $3 \%$ & $6 \%$ & $1 \%$ & $1 \%$ & $0 \%$ \\
\hline
\end{tabular}

Obs. Percentual da variância da variável em consideração explicada pela medida de incerteza no VAR bivariado.

Tabela 10: Testes de auto-correlação serial nos modelos VAR estimados. Medida de incerteza: desvio-padrão das expectativas de crescimento 3 anos à frente.

\begin{tabular}{lccc}
\hline Variável do VAR (além da incerteza) & Defasagens do VAR & Chi2 & P-valor \\
\hline IBC-BR & 3 & 2,81 & 0,58 \\
Confiança do Consumidor & 2 & 4,12 & 0,38 \\
Taxa de Desemprego & 3 & 5,02 & 0,28 \\
Produção Industrial & 3 & 3,77 & 0,43 \\
Vendas a Varejo & 2 & 7,51 & 0,11 \\
CAGED & 3 & 1,23 & 0,87 \\
\hline
\end{tabular}

Obs. O teste apresentado é o de multiplicadores de Lagrange, cuja hipótese nula nula é ausência de auto-correlação serial na respectiva defasagem. $\mathrm{O}$ p-valor se refere à última defasagem do VAR.

\subsection{Variabilidade do mercado acionário}

Quando a incerteza é mensurada pela variabilidade do mercado acionário, a produção industrial é a variável mais afetada, declinando mais de $1 \%$ abaixo da tendência. A confiança do consumidor também recua de forma acentuada, também em magnitude superior a 1\%. O IBC-BR cai cerca de $0,5 \%$ abaixo da tendência, enquanto as demais variáveis exibem uma resposta menos acentuada após a incidência do choque, mas com a dinâmica esperada. Os resultados estão apesentados na figura 7 .

A decomposição da variância, apresentada na tabela 11, mostra novamente que a produção industrial e o IBC-BR são as séries mais afetadas. Mais de $40 \%$ da variância destas séries após 10 meses é explicada pela incerteza identificada pela volatilidade do mercado acionário. Assim como no caso em que a incerteza é mensurada pelo índice, o emprego demora para responder, mas a decomposição da variância indica que transcorridos 10 meses após a incidência do choque de volatilidade cerca de $20 \%$ da variância do emprego é explicada pela incerteza.

Em face das funções de impulso resposta apresentadas para as diversas medidas de incerteza, concluímos que a incerteza afeta negativamente a ativi- 


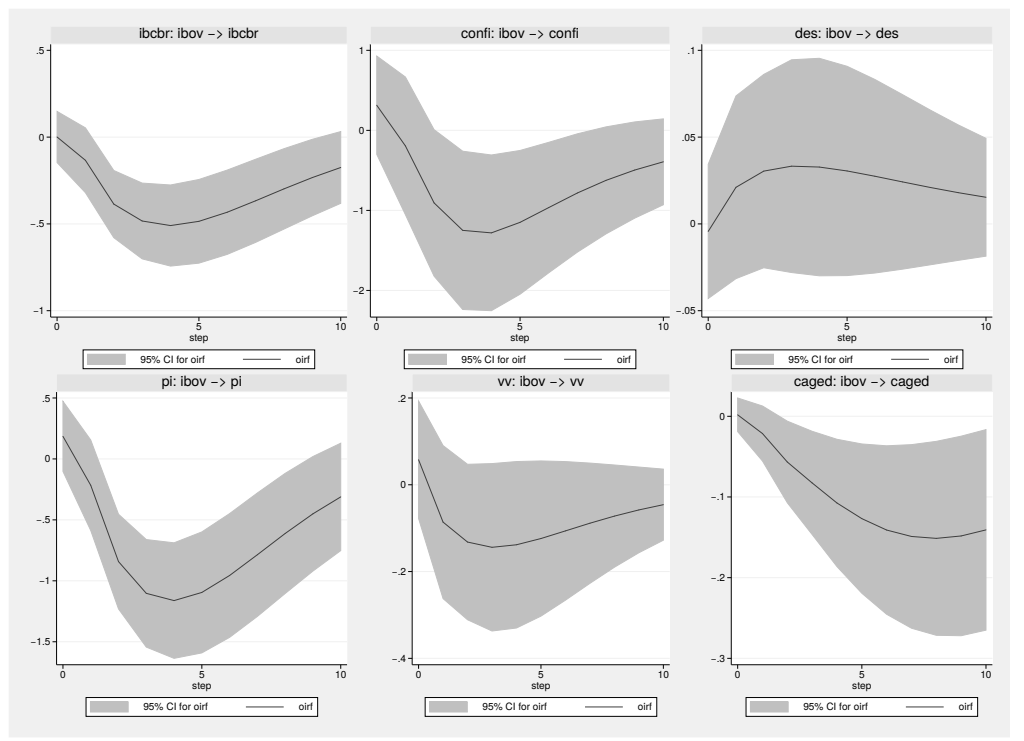

Obs.: Em cima, da esquerda para a direita: resposta do IBC-BR, confiança do consumidor e taxa de desemprego após um choque na volatilidade do IBOVESPA. Embaixo, da esquerda para a direita: resposta da produção industrial, vendas a varejo e CAGED a um choque de incerteza. Eixo vertical em \% da tendência.

Figura 7: Funções de resposta ao impulso dos VARs estimados. Medida de incerteza: volatilidade do IBOVESPA

Tabela 11: Decomposição da variância dos VARs estimados. Medida de incerteza: volatilidade do IBOVESPA.

\begin{tabular}{lcccccc}
\hline $\begin{array}{l}\text { HorizonteIBC-BR } \\
\text { (meses) }\end{array}$ & Confiança & Desemprego & $\begin{array}{l}\text { Produção } \\
\text { Industrial }\end{array}$ & $\begin{array}{c}\text { Vendas } \\
\text { a varejo }\end{array}$ & CAGED \\
\hline 1 & $0 \%$ & $1 \%$ & $0 \%$ & $1 \%$ & $1 \%$ & $0 \%$ \\
2 & $1 \%$ & $1 \%$ & $0 \%$ & $2 \%$ & $1 \%$ & $1 \%$ \\
3 & $10 \%$ & $3 \%$ & $1 \%$ & $12 \%$ & $2 \%$ & $4 \%$ \\
4 & $19 \%$ & $7 \%$ & $2 \%$ & $24 \%$ & $3 \%$ & $7 \%$ \\
5 & $27 \%$ & $10 \%$ & $2 \%$ & $33 \%$ & $4 \%$ & $10 \%$ \\
6 & $33 \%$ & $12 \%$ & $3 \%$ & $39 \%$ & $5 \%$ & $12 \%$ \\
7 & $37 \%$ & $14 \%$ & $3 \%$ & $44 \%$ & $5 \%$ & $15 \%$ \\
8 & $39 \%$ & $15 \%$ & $3 \%$ & $46 \%$ & $6 \%$ & $17 \%$ \\
9 & $41 \%$ & $16 \%$ & $3 \%$ & $48 \%$ & $6 \%$ & $19 \%$ \\
10 & $42 \%$ & $16 \%$ & $3 \%$ & $48 \%$ & $6 \%$ & $21 \%$ \\
\hline
\end{tabular}

Obs. Percentual da variância da variável em consideração explicada pela volatilidade do IBOVESPA no VAR bivariado. 
Tabela 12: Testes de auto-correlação serial nos modelos VAR estimados. Medida de incerteza: volatilidade do IBOVESPA.

\begin{tabular}{lccc}
\hline Variável do VAR (além da incerteza) & Defasagens do VAR & Chi2 & P-valor \\
\hline IBC-BR & 2 & 7,06 & 0,13 \\
Confiança do Consumidor & 2 & 2,74 & 0,60 \\
Taxa de Desemprego & 2 & 0,96 & 0,91 \\
Produção Industrial & 2 & 3,86 & 0,42 \\
Vendas a Varejo & 2 & 2,98 & 0,55 \\
CAGED & 3 & 7,51 & 0,11 \\
\hline Obs. O teste apresentado é o de multiplicadores de Lagrange, cuja hipótese nula nula \\
é ausência de auto-correlação serial na respectiva defasagem. O p-valor se refere à \\
última defasagem do VAR.
\end{tabular}

dade econômica no Brasil. Os resultados obtidos para as três proxies de incerteza estão em linha com as expectativas. Em termos individuais, a produção industrial, o IBC-BR e a confiança do consumidor são as séries mais afetadas por choques de incerteza.

Adicionalmente, as funções de impulso resposta mostram que os choques de incerteza são transmitidos de forma rápida para a economia, não levando mais de 5 meses para produzirem o seu efeito máximo.

\section{Comparação entre choques de incerteza e choques na taxa de juros}

Tendo em vista o efeito negativo de um aumento da incerteza na economia brasileira, o passo natural é questionar como os efeitos de um choque de incerteza se comparam aos choques tradicionais usualmente analisados pelos economistas, como um choque monetário. Desse modo, foram estimados VARs aumentados, incluindo outras variáveis além da medida de incerteza e o indicador de atividade econômica. Como os resultados apresentados na seção anterior apontaram para uma maior reação do IBC-BR, da confiança do consumidor e da produção industrial, estas variáveis foram consideradas como indicadores de atividade econômica nos modelos estimados nesta seção. Embora a confiança do consumidor não seja uma medida de produção propriamente dita, pode ser entendida como um indicador da intenção de demanda das famílias.

Tomando como ponto de partida os estudos de Minella (2003) $)^{8}$ e Luporini (2008) sobre a política monetária no contexto dos modelos VAR, esta seção apresenta os resultados obtidos a partir da estimação de diversos modelos VAR, seguindo a ordenação das variáveis empregadas nesses estudos. Assim, a primeira ordenação utilizada foi seguinte: incerteza, indicador de atividade econômica, taxa de inflação medida pelo IPCA e taxa Selic. A segunda ordenação seguiu o estudo de Luporini (2008): incerteza, indicador de atividade econômica, taxa de inflação medida pelo IPCA, variação cambial nominal da taxa de câmbio BRL/USD para um determinado mês e taxa Selic. As ordens consideradas implicam que a incerteza afeta contemporaneamente as demais variáveis, mas não é afetada por elas. Esta opção está em consonância com a evidência internacional, como, por exemplo, em Denis \& Kannan (2013) e

\footnotetext{
${ }^{8} \mathrm{~A}$ ordenação básica do referido artigo considera o agregado M1, que não foi considerada aqui.
} 
Bloom (2009). Por sua vez, a taxa Selic foi ordenada em último nos VARs, como medida de política monetária. Assim, a ordenação do VAR implica que a Selic responde contemporaneamente à incerteza e às demais variáveis do VAR.

As séries utilizadas na estimação dos VARs estão apresentadas na figura 2. As medidas de incerteza utilizadas foram as apresentadas na seção 2: índice de incerteza baseado em jornais, desvio-padrão das expectativas de crescimento para 1 e 2 anos à frente, e volatilidade do IBOVESPA. Cada VAR foi estimado com uma medida de incerteza e um indicador de atividade de cada vez, e com as duas ordenações mencionadas. A seguir detalhamos a resposta obtida para cada medida de incerteza.

\section{1 Índice de incerteza}

A figura 8 apresenta as funções de impulso resposta do VAR ampliado seguindo a primeira ordenação. A parte superior mostra a resposta das medidas de atividade a um choque de incerteza no índice, enquanto a parte inferior mostra a resposta das mesmas variáveis a um choque na taxa Selic. Sob um choque de incerteza, o IBC-BR, a confiança do consumidor e a produção industrial recuam $0,4 \%, 1 \%$ e $1 \%$, respectivamente, enquanto que após um choque na taxa Selic as respostas têm magnitude bastante inferior e bem mais suave.

A figura 9 apresenta os resultados para a segunda ordenação do VAR, que considera também a variação cambial. Os resultados qualitativos são bastante semelhantes aos da primeira ordenação, no sentido de que após um choque de incerteza a contração da atividade ocorre de forma rápida, demorando menos do que 5 meses para se materializar de forma máxima. A magnitude da contração também surpreende, uma vez que o efeito na atividade após um choque de incerteza é grosso modo o dobro do obtido após um choque na taxa Selic. Após um choque ortogonalizado de incerteza, o IBC-BR declina 0,4\%, enquanto que após um choque ortogonalizado na taxa Selic a queda estimada não supera $0,2 \%$.

\subsection{Desvio-padrão das expectativas de crescimento econômico}

As figuras 10 e 12 apresentam as funções de impulso resposta do VAR ampliado seguindo a primeira ordenação, para o desvio-padrão das expectativas de crescimento para 1 e 2 anos à frente, respectivamente. Os painéis superiores apresentam as respostas obtidas após um choque de incerteza, enquanto os painéis inferiores apresentam as respostas para um choque na taxa Selic.

Novamente, o mesmo padrão qualitativo observado para a subseção anterior, quanto a incerteza foi medida pelo índice, se repete. Um choque de incerteza leva a uma queda da atividade de forma mais rápida e mais profunda do que um choque na taxa Selic. Em termos quantitativos, a resposta do IBC-BR e da produção industrial a um choque de incerteza é quase o dobro da observada após um choque na taxa Selic.

As figuras 11 e 13 apresentam as funções de impulso resposta a partir da segunda ordenação, e também consideram a variação cambial nominal no VAR. 


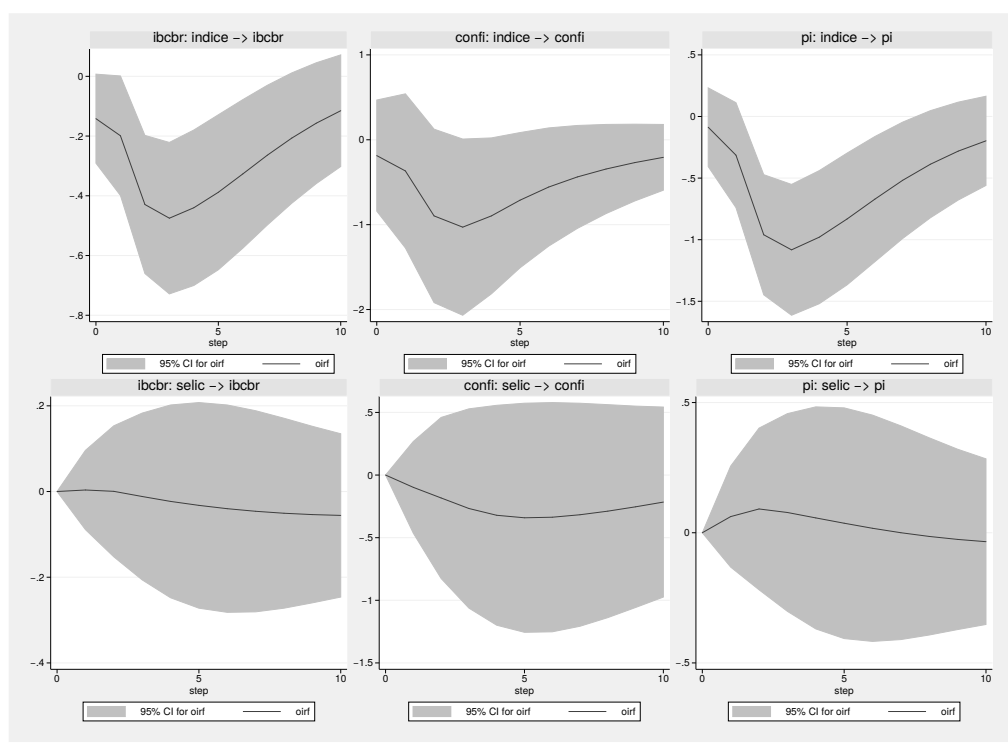

Em cima: resposta do IBC-BR, confiança do consumidor e produção industrial a um choque de incerteza. Embaixo: resposta das mesmas variáveis a um choque na taxa Selic.

Figura 8: Funções de resposta ao impulso do VAR ampliado (ordem: incerteza, atividade, IPCA e Selic). Medida de incerteza: índice

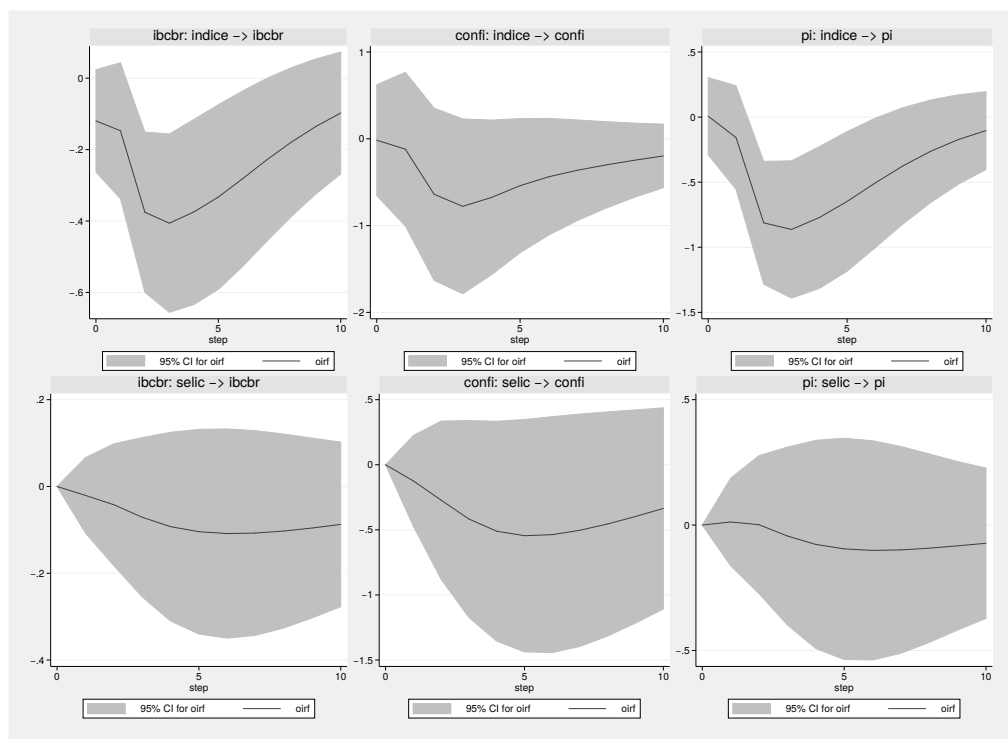

Em cima: resposta do IBC-BR, confiança do consumidor e produção industrial a um choque de incerteza. Embaixo: resposta das mesmas variáveis a um choque na taxa Selic.

Figura 9: Funções de resposta ao impulso do VAR ampliado (ordem: incerteza, atividade, IPCA, variação cambial e Selic). Medida de incerteza: índice 

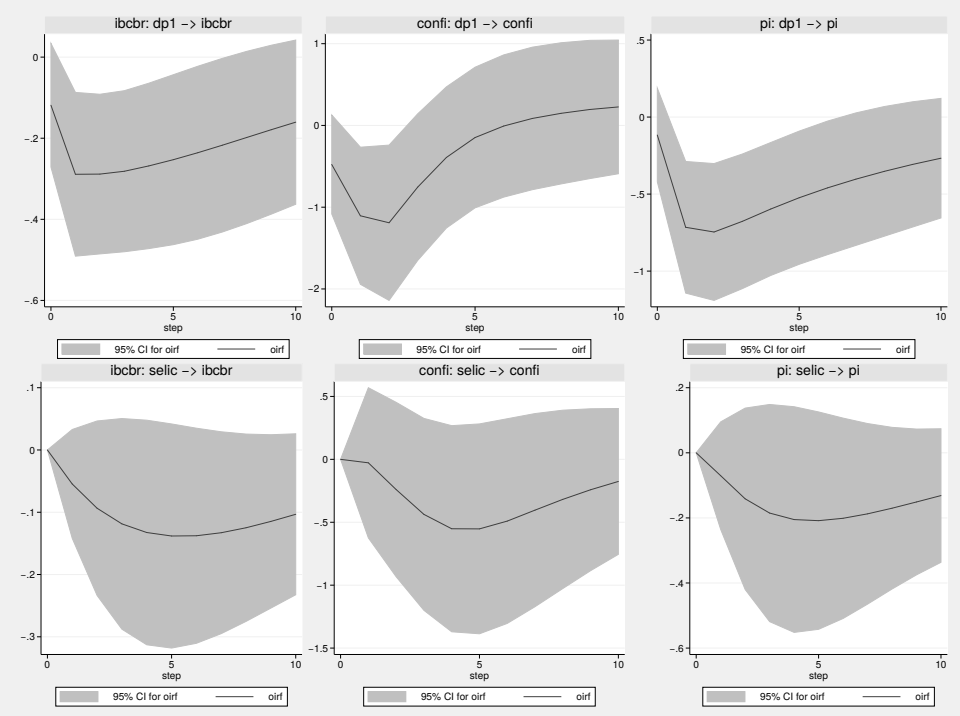

Em cima: resposta do IBC-BR, confiança do consumidor e produção industrial a um choque de incerteza. Embaixo: resposta das mesmas variáveis a um choque na taxa Selic.

Figura 10: Funções de resposta ao impulso do VAR ampliado (ordem: incerteza, atividade, IPCA e Selic). Medida de incerteza: desviopadrão das expectativas de crescimento 1 ano à frente
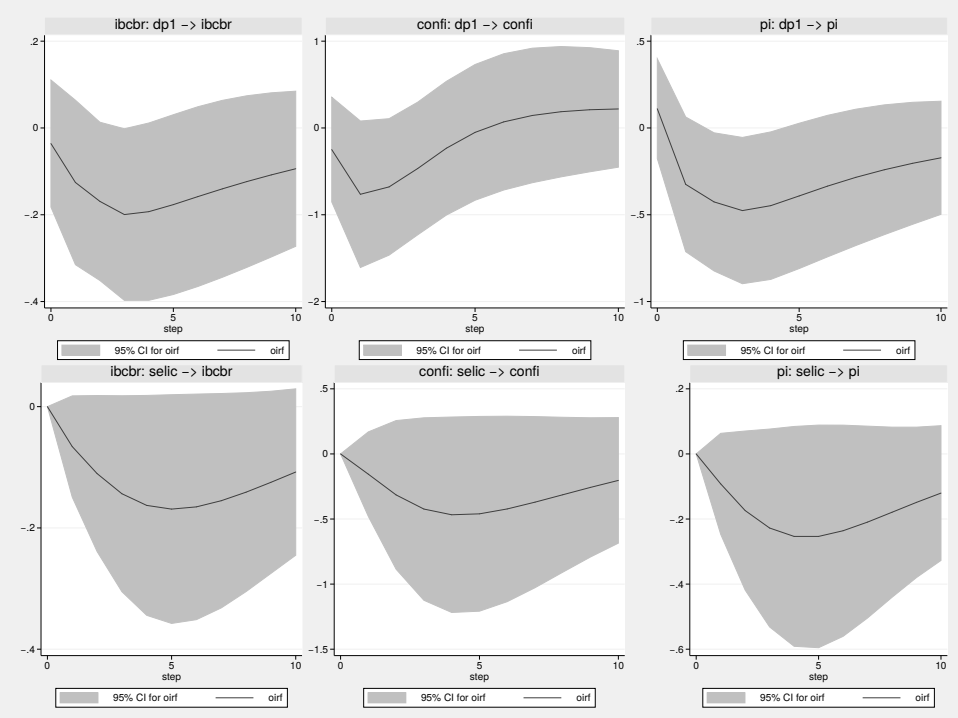

Em cima: resposta do IBC-BR, confiança do consumidor e produção industrial a um choque de incerteza. Embaixo: resposta das mesmas variáveis a um choque na taxa Selic.

Figura 11: Funções de resposta ao impulso do VAR ampliado (ordem: incerteza, atividade, IPCA, variação cambial e Selic). Medida de incerteza: desvio-padrão das expectativas de crescimento 1 ano à frente 


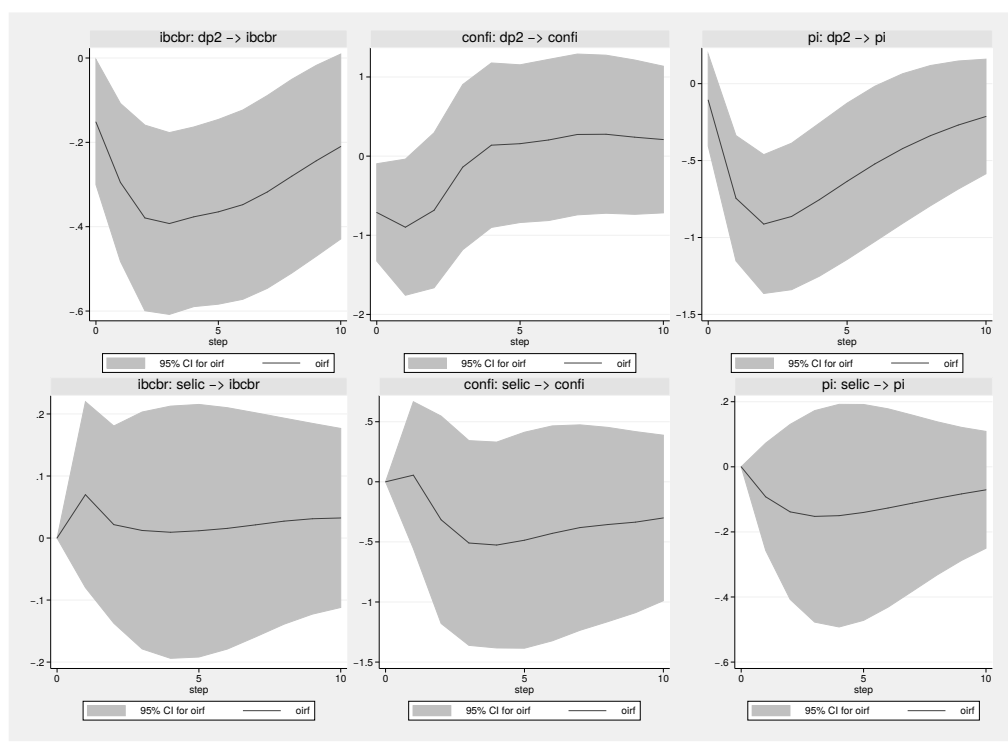

Em cima: resposta do IBC-BR, confiança do consumidor e produção industrial a um choque de incerteza. Embaixo: resposta das mesmas variáveis a um choque na taxa Selic.

Figura 12: Funções de resposta ao impulso do VAR ampliado (ordem: incerteza, atividade, IPCA e Selic). Medida de incerteza: desviopadrão das expectativas de crescimento 2 anos à frente

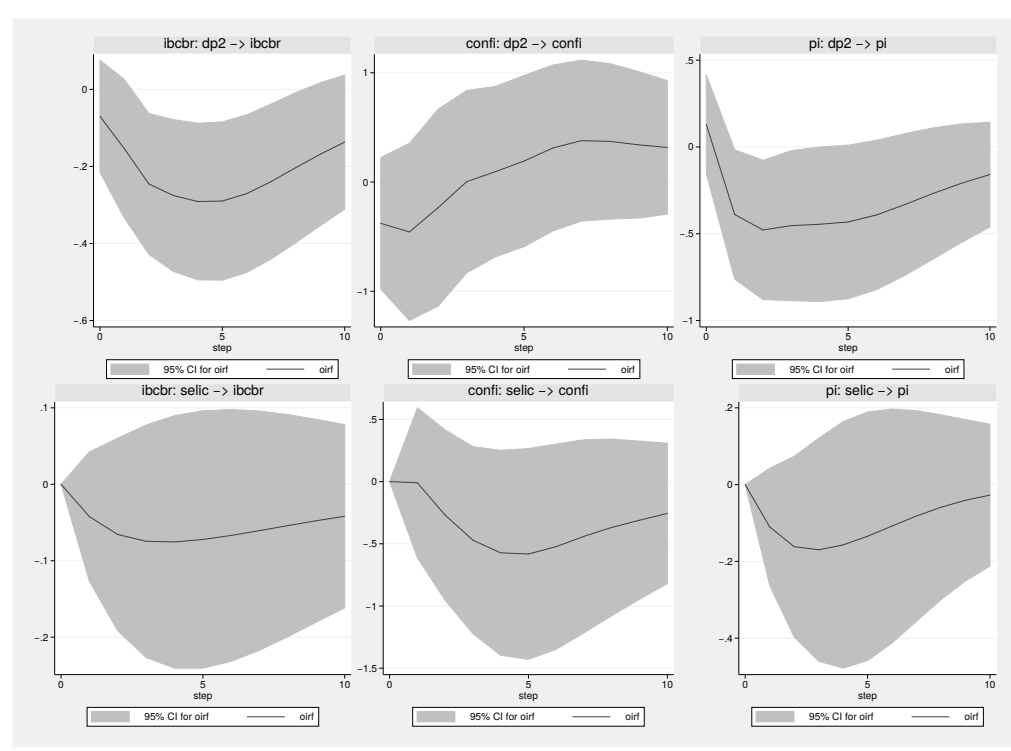

Em cima: resposta do IBC-BR, confiança do consumidor e produção industrial a um choque de incerteza. Embaixo: resposta das mesmas variáveis a um choque na taxa Selic.

Figura 13: Funções de resposta ao impulso do VAR ampliado (ordem: incerteza, atividade, IPCA, variação cambial e Selic). Medida de incerteza: desvio-padrão das expectativas de crescimento 2 anos à frente 


\subsection{Volatilidade do IBOVESPA}

As figuras 14 e 15 mostram as funções de impulso resposta para as duas ordenações, considerando como medida de incerteza a volatilidade do IBOVESPA. O contraste entre o formato da resposta de uma mesma variável aos dois choques de natureza distinta é claro. Para a produção industrial, a resposta após um choque de incerteza tem formato de $\mathrm{V}$, recuando mais de $1 \%$ abaixo da tendência. A resposta após um choque na taxa Selic é bem mais suave e quantitativamente inferior, não superando $-0,2 \%$.

Assim, os resultados apontam para um mesmo padrão qualitativo para as funções de impulso resposta após um choque de incerteza, mostrando que choques de incerteza produzem efeitos rápidos e profundos na atividade econômica no Brasil.

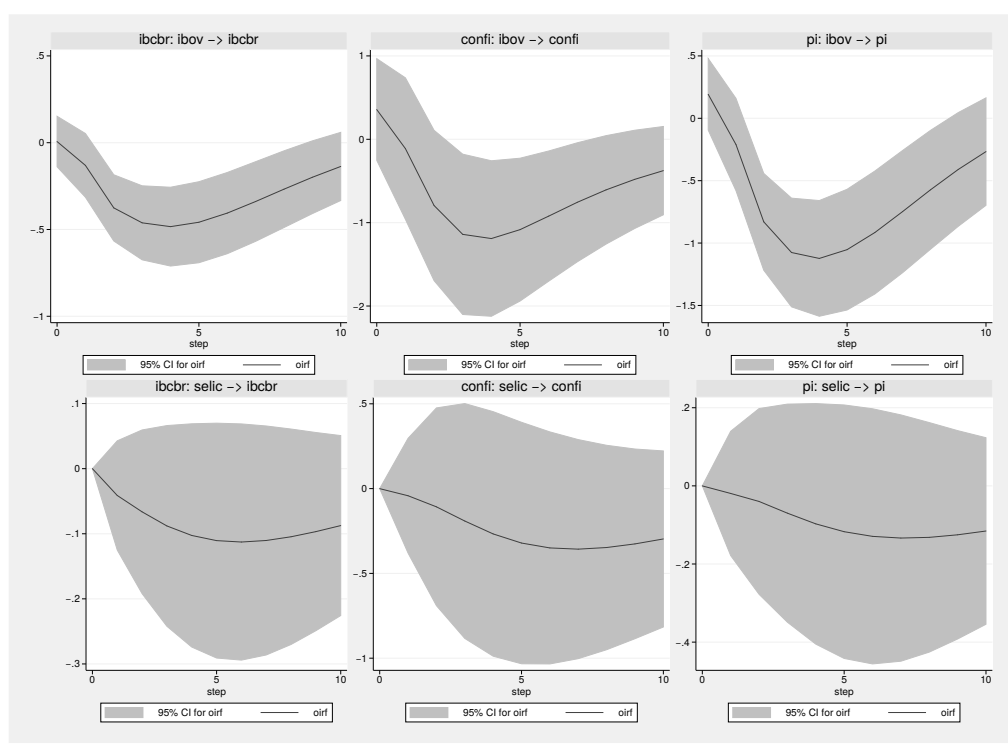

Em cima: resposta do IBC-BR, confiança do consumidor e produção industrial a um choque de incerteza. Embaixo: resposta das mesmas variáveis a um choque na taxa Selic.

Figura 14: Funções de resposta ao impulso do VAR ampliado (ordem: incerteza, atividade, IPCA e Selic). Medida de incerteza: volatilidade do IBOVESPA

\subsection{Decomposição da variância}

Outra forma de se avaliar a importância de choques de incerteza para a atividade econômica é por meio da decomposição da variância do erro de previsão, que dá a proporção dos movimentos em uma variável em função dos diferentes choques no VAR. A tabela 13 mostra a decomposição da variância do IBC-BR e da produção industrial quando os VARs foram estimados utilizando a primeira ordenação (incerteza, atividade, IPCA e Selic) para a decomposição de Choleski. Por sua vez, a tabela 14 apresenta a decomposição da variância para as variáveis mencionadas quando os VARs foram estimados utilizando a segunda ordenação (incerteza, atividade, IPCA, variação cambial e Selic). 


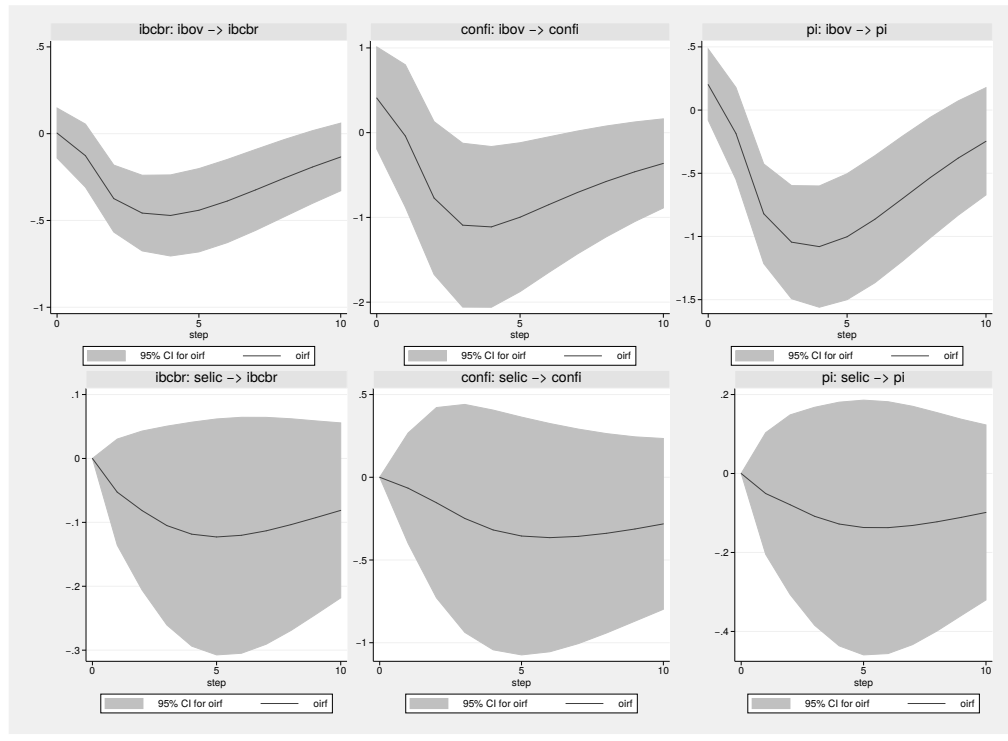

Em cima: resposta do IBC-BR, confiança do consumidor e produção industrial a um choque de incerteza. Embaixo: resposta das mesmas variáveis a um choque na taxa Selic.

Figura 15: Funções de resposta ao impulso do VAR ampliado (ordem: incerteza, atividade, IPCA, variação cambial e Selic). Medida de incerteza: volatilidade do IBOVESPA

Para a primeira ordenação, que seguiu Minella (2003), os resultados mostram uma grande importância para os choques de incerteza na atividade econômica, oscilando entre 20 a 45\%, dependendo da medida de incerteza.

Para a segunda ordenação, que seguiu Luporini (2008), os resultados mostram que a incerteza perde papel relativo para a variação cambial na decomposição da variância, mas permanece tendo elevada relevância, com o percentual oscilando entre 10 e $40 \%$, dependendo da medida de incerteza considerada. A variação cambial responde por cerca de $20 \%$ do IBC-BR e da produção industrial quando a incerteza é mensurada pelo índice ou pelo desvio-padrão das expectativas de crescimento. Entretanto, quando a incerteza é mensurada pelo mercado acionário, a contribuição da variação cambial na decomposição da variância é pequena.

Curiosamente, os resultados não apontam para uma grande contribuição dos choques na taxa Selic para a variabilidade das séries consideradas, em comparação com os choques nas demais variáveis do VAR. 
Tabela 13: Decomposição da variância dos VARs estimados com a ordem de Minella (2003)

\begin{tabular}{|c|c|c|c|c|c|c|c|c|}
\hline \multirow[t]{3}{*}{ Meses } & \multicolumn{4}{|c|}{ VAR: Índice, atividade, IPCA, Selic } & \multicolumn{4}{|c|}{ VAR: DP1, atividade, IPCA e Selic } \\
\hline & \multicolumn{2}{|c|}{ Impulso no índice } & \multicolumn{2}{|c|}{ Impulso na Selic } & \multicolumn{2}{|c|}{ Impulso no DP1 } & \multicolumn{2}{|c|}{ Impulso na Selic } \\
\hline & IBC-BR & PI & IBC-BR & PI & IBC-BR & PI & IBC-BR & PI \\
\hline 1 & $3 \%$ & $0 \%$ & $0 \%$ & $0 \%$ & $2 \%$ & $0 \%$ & $0 \%$ & $0 \%$ \\
\hline 2 & $5 \%$ & $2 \%$ & $0 \%$ & $0 \%$ & $7 \%$ & $8 \%$ & $0 \%$ & $0 \%$ \\
\hline 3 & $13 \%$ & $13 \%$ & $0 \%$ & $0 \%$ & $9 \%$ & $12 \%$ & $1 \%$ & $0 \%$ \\
\hline 4 & $20 \%$ & $21 \%$ & $0 \%$ & $0 \%$ & $12 \%$ & $15 \%$ & $1 \%$ & $1 \%$ \\
\hline 5 & $24 \%$ & $26 \%$ & $0 \%$ & $0 \%$ & $13 \%$ & $16 \%$ & $2 \%$ & $1 \%$ \\
\hline 6 & $26 \%$ & $29 \%$ & $0 \%$ & $0 \%$ & $15 \%$ & $18 \%$ & $2 \%$ & $1 \%$ \\
\hline 7 & $28 \%$ & $31 \%$ & $0 \%$ & $0 \%$ & $16 \%$ & $19 \%$ & $3 \%$ & $1 \%$ \\
\hline 8 & $29 \%$ & $32 \%$ & $0 \%$ & $0 \%$ & $17 \%$ & $20 \%$ & $3 \%$ & $2 \%$ \\
\hline 9 & $29 \%$ & $32 \%$ & $0 \%$ & $0 \%$ & $18 \%$ & $20 \%$ & $4 \%$ & $2 \%$ \\
\hline 10 & $30 \%$ & $33 \%$ & $0 \%$ & $0 \%$ & $19 \%$ & $21 \%$ & $4 \%$ & $2 \%$ \\
\hline \multirow[t]{3}{*}{ Meses } & \multicolumn{4}{|c|}{ VAR: DP2, atividade, IPCA e Selic } & \multicolumn{4}{|c|}{ VAR: IBOV, Atividade, IPCA e Selic } \\
\hline & \multicolumn{2}{|c|}{ Impulso no DP2 } & \multicolumn{2}{|c|}{ Impulso na Selic } & \multicolumn{2}{|c|}{ Impulso no IBOV } & \multicolumn{2}{|c|}{ Impulso na Selic } \\
\hline & IBC-BR & PI & IBC-BR & PI & IBC-BR & PI & IBC-BR & PI \\
\hline 1 & $3 \%$ & $0 \%$ & $0 \%$ & $0 \%$ & $0 \%$ & $1 \%$ & $0 \%$ & $0 \%$ \\
\hline 2 & $8 \%$ & $9 \%$ & $0 \%$ & $0 \%$ & $1 \%$ & $2 \%$ & $0 \%$ & $0 \%$ \\
\hline 3 & $14 \%$ & $16 \%$ & $0 \%$ & $0 \%$ & $10 \%$ & $12 \%$ & $0 \%$ & $0 \%$ \\
\hline 4 & $18 \%$ & $21 \%$ & $0 \%$ & $0 \%$ & $18 \%$ & $23 \%$ & $1 \%$ & $0 \%$ \\
\hline 5 & $22 \%$ & $23 \%$ & $0 \%$ & $1 \%$ & $25 \%$ & $32 \%$ & $1 \%$ & $0 \%$ \\
\hline 6 & $26 \%$ & $25 \%$ & $0 \%$ & $1 \%$ & $31 \%$ & $38 \%$ & $1 \%$ & $0 \%$ \\
\hline 7 & $29 \%$ & $26 \%$ & $0 \%$ & $1 \%$ & $34 \%$ & $42 \%$ & $2 \%$ & $0 \%$ \\
\hline 8 & $31 \%$ & $27 \%$ & $0 \%$ & $1 \%$ & $36 \%$ & $44 \%$ & $2 \%$ & $1 \%$ \\
\hline 9 & $33 \%$ & $27 \%$ & $0 \%$ & $1 \%$ & $38 \%$ & $46 \%$ & $2 \%$ & $1 \%$ \\
\hline 10 & $34 \%$ & $28 \%$ & $0 \%$ & $1 \%$ & $38 \%$ & $46 \%$ & $3 \%$ & $1 \%$ \\
\hline
\end{tabular}


Tabela 14: Decomposição da variância dos VARs estimados com a ordem de Luporini

\begin{tabular}{|c|c|c|c|c|c|c|c|c|c|c|c|c|}
\hline \multirow[t]{3}{*}{ Meses } & \multicolumn{6}{|c|}{ VAR: Índice, atividade, IPCA, var cambial e Selic } & \multicolumn{6}{|c|}{ VAR: DP1, atividade, IPCA, var cambial e Selic } \\
\hline & \multicolumn{2}{|c|}{ Impulso no Índice } & \multicolumn{2}{|c|}{ Impulso na Selic } & \multicolumn{2}{|c|}{ Impulso no câmbio } & \multicolumn{2}{|c|}{ Impulso no DP1 } & \multicolumn{2}{|c|}{ Impulso na Selic } & \multicolumn{2}{|c|}{ Impulso no câmbio } \\
\hline & IBC-BR & PI & IBC-BR & PI & IBC-BR & PI & IBC-BR & PI & IBC-BR & PI & IBC-BR & PI \\
\hline 1 & $2 \%$ & $0 \%$ & $0 \%$ & $0 \%$ & $0 \%$ & $0 \%$ & $0 \%$ & $0 \%$ & $0 \%$ & $0 \%$ & $0 \%$ & $0 \%$ \\
\hline 2 & $3 \%$ & $1 \%$ & $0 \%$ & $0 \%$ & $2 \%$ & $7 \%$ & $1 \%$ & $2 \%$ & $0 \%$ & $0 \%$ & $1 \%$ & $3 \%$ \\
\hline 3 & $10 \%$ & $9 \%$ & $0 \%$ & $0 \%$ & $7 \%$ & $13 \%$ & $3 \%$ & $4 \%$ & $1 \%$ & $1 \%$ & $7 \%$ & $12 \%$ \\
\hline 4 & $15 \%$ & $14 \%$ & $0 \%$ & $0 \%$ & $10 \%$ & $17 \%$ & $4 \%$ & $5 \%$ & $2 \%$ & $1 \%$ & $11 \%$ & $17 \%$ \\
\hline 5 & $17 \%$ & $17 \%$ & $1 \%$ & $0 \%$ & $12 \%$ & $19 \%$ & $5 \%$ & $6 \%$ & $2 \%$ & $1 \%$ & $14 \%$ & $20 \%$ \\
\hline 6 & $19 \%$ & $18 \%$ & $1 \%$ & $0 \%$ & $13 \%$ & $21 \%$ & $6 \%$ & $7 \%$ & $3 \%$ & $2 \%$ & $15 \%$ & $21 \%$ \\
\hline 7 & $20 \%$ & $19 \%$ & $1 \%$ & $0 \%$ & $13 \%$ & $21 \%$ & $6 \%$ & $8 \%$ & $4 \%$ & $2 \%$ & $16 \%$ & $22 \%$ \\
\hline 8 & $21 \%$ & $20 \%$ & $1 \%$ & $0 \%$ & $13 \%$ & $21 \%$ & $6 \%$ & $8 \%$ & $5 \%$ & $2 \%$ & $16 \%$ & $22 \%$ \\
\hline 9 & $21 \%$ & $20 \%$ & $2 \%$ & $0 \%$ & $13 \%$ & $21 \%$ & $7 \%$ & $9 \%$ & $5 \%$ & $3 \%$ & $16 \%$ & $22 \%$ \\
\hline 10 & $22 \%$ & $20 \%$ & $2 \%$ & $0 \%$ & $13 \%$ & $21 \%$ & $7 \%$ & $9 \%$ & $6 \%$ & $3 \%$ & $17 \%$ & $22 \%$ \\
\hline \multirow[t]{3}{*}{ Meses } & \multicolumn{6}{|c|}{ VAR: DP2, atividade, IPCA, var cambial e Selic } & \multicolumn{6}{|c|}{ VAR: ibov, atividade, IPCA, var cambial e Selic } \\
\hline & \multicolumn{2}{|c|}{ Impulso no DP2 } & \multicolumn{2}{|c|}{ Impulso na Selic } & \multicolumn{2}{|c|}{ Impulso no câmbio } & \multicolumn{2}{|c|}{ Impulso no ibov } & \multicolumn{2}{|c|}{ Impulso na Selic } & \multicolumn{2}{|c|}{ Impulso no câmbio } \\
\hline & IBC-BR & PI & IBC-BR & PI & IBC-BR & PI & IBC-BR & PI & IBC-BR & PI & IBC-BR & PI \\
\hline 1 & $1 \%$ & $1 \%$ & $0 \%$ & $0 \%$ & $0 \%$ & $0 \%$ & $0 \%$ & $2 \%$ & $0 \%$ & $0 \%$ & $0 \%$ & $0 \%$ \\
\hline 2 & $2 \%$ & $3 \%$ & $0 \%$ & $0 \%$ & $1 \%$ & $2 \%$ & $1 \%$ & $2 \%$ & $0 \%$ & $0 \%$ & $0 \%$ & $1 \%$ \\
\hline 3 & $3 \%$ & $5 \%$ & $1 \%$ & $1 \%$ & $5 \%$ & $9 \%$ & $10 \%$ & $11 \%$ & $1 \%$ & $0 \%$ & $1 \%$ & $3 \%$ \\
\hline 4 & $3 \%$ & $6 \%$ & $1 \%$ & $1 \%$ & $9 \%$ & $15 \%$ & $18 \%$ & $21 \%$ & $1 \%$ & $0 \%$ & $2 \%$ & $3 \%$ \\
\hline 5 & $5 \%$ & $7 \%$ & $0 \%$ & $1 \%$ & $12 \%$ & $19 \%$ & $24 \%$ & $29 \%$ & $1 \%$ & $0 \%$ & $2 \%$ & $3 \%$ \\
\hline 6 & $7 \%$ & $8 \%$ & $0 \%$ & $1 \%$ & $13 \%$ & $20 \%$ & $29 \%$ & $35 \%$ & $2 \%$ & $0 \%$ & $2 \%$ & $3 \%$ \\
\hline 7 & $10 \%$ & $9 \%$ & $1 \%$ & $1 \%$ & $14 \%$ & $21 \%$ & $32 \%$ & $38 \%$ & $2 \%$ & $1 \%$ & $1 \%$ & $3 \%$ \\
\hline 8 & $13 \%$ & $9 \%$ & $1 \%$ & $1 \%$ & $15 \%$ & $21 \%$ & $34 \%$ & $40 \%$ & $3 \%$ & $1 \%$ & $1 \%$ & $3 \%$ \\
\hline 9 & $15 \%$ & $10 \%$ & $1 \%$ & $1 \%$ & $15 \%$ & $21 \%$ & $35 \%$ & $42 \%$ & $3 \%$ & $1 \%$ & $1 \%$ & $3 \%$ \\
\hline 10 & $17 \%$ & $10 \%$ & $1 \%$ & $1 \%$ & $16 \%$ & $21 \%$ & $36 \%$ & $42 \%$ & $3 \%$ & $1 \%$ & $1 \%$ & $3 \%$ \\
\hline
\end{tabular}


Tabela 15: Testes de auto-correlação serial nos modelos VAR ampliados

\begin{tabular}{llll}
\hline Índice-IBC-BR-IPCA-Selic & 2 & 21,11 & 0,17 \\
Índice-Confiança-IPCA-Selic & 2 & 19,07 & 0,26 \\
Índice-PI-IPCA-Selic & 2 & 14,37 & 0,57 \\
Índice-IBC-BR-IPCA-Var Cambial-Selic & 2 & 31,40 & 0,17 \\
Índice-Confiança-IPCA-Var, Cambial-Selic & 2 & 31,23 & 0,18 \\
Índice-PI-IPCA-Var, Cambial- Selic & 2 & 31,73 & 0,16 \\
DP1-IBC-BR-IPCA-Selic & 2 & 21,68 & 0,15 \\
DP1-Confiança-IPCA-Selic & 2 & 22,92 & 0,11 \\
DP1-PI-IPCA-Selic & 2 & 11,12 & 0,80 \\
DP1-IBC-BR-IPCA-Var Cambial-Selic & 2 & 28,60 & 0,28 \\
DP1-Confiança-IPCA-Var, Cambial-Selic & 2 & 31,64 & 0,16 \\
DP1-PI-IPCA-Var, Cambial- Selic & 2 & 22,53 & 0,60 \\
DP2-IBC-BR-IPCA-Selic & 3 & 23,52 & 0,10 \\
DP2-Confiança-IPCA-Selic & 4 & 21,59 & 0,15 \\
DP2-PI-IPCA-Selic & 2 & 23,21 & 0,10 \\
DP2-IBC-BR-IPCA-Var Cambial-Selic & 2 & 42,41 & 0,01 \\
DP2-Confiança-IPCA-Var, Cambial-Selic & 3 & 40,58 & 0,02 \\
DP2-PI-IPCA-Var, Cambial- Selic & 2 & 44,05 & 0,01 \\
Ibov-IBC-BR-IPCA-Selic & 2 & 18,51 & 0,29 \\
Ibov-Confiança-IPCA-Selic & 2 & 17,48 & 0,35 \\
Ibov-PI-IPCA-Selic & 2 & 13,29 & 0,65 \\
Ibov-IBC-BR-IPCA-Var Cambial-Selic & 2 & 30,01 & 0,22 \\
Ibov-Confiança-IPCA-Var, Cambial-Selic & 2 & 20,03 & 0,74 \\
Ibov-PI-IPCA-Var, Cambial- Selic & 2 & 25,04 & 0,45 \\
\hline Obs. O teste apresentado é o de multiplicadores de Lagrange, \\
cuja hipótese nula nula é ausência de auto-correlação serial na \\
respectiva defasagem. O p-valor se refere à última defasagem \\
do VAR. & & & \\
& & &
\end{tabular}

\section{Conclusão}

Este trabalho contribui para as evidências de choques na incerteza em variáveis macroeconômicas relacionadas à atividade econômica no Brasil, à luz da crescente pesquisa internacional a respeito do tema.

Foram exploradas as 3 medidas de incerteza encontradas na literatura: a frequência de artigos relacionados à incerteza nos jornais, a variabilidade das expectativas de crescimento e a volatilidade do mercado acionário. Mostrouse que, em linha com o observado para outros países, a incerteza em geral é contra-cíclica, de forma que períodos de maior incerteza são períodos de atividade econômica deprimida, com choques de incerteza exercendo o maior efeito na produção industrial, IBC-BR e confiança do consumidor.

Embora a confiança do consumidor não seja uma medida de produção propriamente dita, os resultados sugerem uma relação entre choques de incerteza e choques de confiança.

Adicionalmente, choques de incerteza são relevantes para explicar a dinâmica da atividade econômica no Brasil, tendo em vista os resultados obtidos para as decomposições da variância nos VARs estimados, e produzem consequências mais profundas e velozes na economia brasileira, em comparação com choques monetários. Esses resultados estão em linha com os obtidos por Denis \& Kannan (2013) para o Reino Unido e Bloom (2009) e Alexopoulos \& Cohen (2009) para os Estados Unidos. 


\section{Agradecimentos}

Agradeço ao parecerista anônimo, pelas importantes sugestões, a à empresa EBC, que permitiu o acesso à base de dados do Clipping de Notícias da Radiobrás, possibilitando a construção do índice.

\section{Referências Bibliográficas}

Alexopoulos, M. \& Cohen, J. (2009), 'Uncertain times, uncertain measures', Working Papers 352, University of Toronto, Department of Economics .

Bachmann, R., Steffen, E. \& Sims, E. R. (2013), 'Uncertainty and economic activity: Evidence from business survey data', American Economic Journal: Macroeconomics 5(2), 217-249.

Baker, S., Bloom, N. \& Davis, S. J. (2013), Measuring economic policy uncertainty, Technical report, University of Chicago and Stanford University.

URL: www.policyuncertainty.com

Bernanke, B. (1983), 'Irreversibility, uncertainty and cyclical investment', Quarterly Journal of Economics 98, 85-106.

Bloom, N. (2009), 'The impact of uncertainty shocks', Econometrica 77, 62385.

Bloom, N. (2014), 'Fluctuations in uncertainty', Journal of Economic Perspectives, American Economic Association 28(2), 153-76. Spring.

Denis, S. \& Kannan, P. (2013), 'The impact of uncertainty shocks on the uk economy', IMF Working Paper (13/66).

Guerron-Quintana, P. A. (2012), 'Risk and uncertainty', Business Review, Federal Reserve Bank of Philadelphia (Q1), 9-18.

Haddow, A., Hare, C., Hooley, J. \& Shakir, T. (2013), 'Macroeconomic uncertainty; what is it, how can we measure it and why does it matter?', Bank of England Quarterly Bulletin 53(2), 100-109.

Luporini, V. (2008), 'The monetary transmission mechanism in brazil: evidence from a var analysis', Estud. Econ., São Paulo 38(1).

Minella, A. (2003), 'Monetary policy and inflation in brazil (1975-2000): a var estimation', Rev. Bras. Econ. [online] 57(3), 605-635.

Minella, A., Freitas, P., Goldfajn, I. \& Muinhos, M. K. (2003), Inflation targeting in brazil: Constructing credibility under exchange rate volatility, Technical report, Working Papers Series 77, Central Bank of Brazil, Research Department.

Romer, C. (1990), 'The great crash and the onset of the great depression', Quarterly Journal of Economics 105, 597-624.

Silva Filho, T. N. T. (2007), 'Is the investment-uncertainty link really elusive? the harmful effects of inflation uncertainty in brazil', Working Papers Series 157, Central Bank of Brazil, Research Department. 


\section{Apêndice A}

As tabelas A.1 e A.2 apresentam os testes de raiz unitária nas séries utilizadas na pesquisa. São apresentados os testes de Philips-Perron e Dick-Fuller GLS. A hipótese nula de ambos os testes é de presença de raiz unitária nas séries. No teste Dick-Fuller GLS, a série de tempo a ser testada primeiramente é transformada por meio do procedimento de mínimos quadrados generalizados. A série a ser testada é regredida em uma constante e uma tendência linear, e aplica-se um teste ADF aos resíduos da regressão. Como as séries utilizadas não aparentam ter uma tendência, a versão do teste utilizada considerou apenas uma constante na primeira etapa, ou seja, foi utilizado o procedimento de GLS demeaning em vez de GLS detrending. ${ }^{9}$ A principal vantagem deste teste em comparação com os testes de Dick-Fuller aumentado e o teste de PhilipsPerron é o seu maior poder.

O teste de Philips-Perron indica a presença de raiz unitária nas séries do CAGED, taxa Selic e no desvio-padrão das expectativas de crescimento para 3 anos à frente. Por sua vez, o teste Dick-Fuller GLS indica que quase todas as séries são estacionárias, com exceção das vendas a varejo, IPCA e taxa Selic. Apesar disso, nos resultados apresentados acima considerou-se que as séries são estacionárias.

Uma possível fonte de discussão ou questionamento se refere à dependência dos resultados apresentados em relação à ordem de integração da taxa Selic. No artigo considerou-se que a taxa Selic é estacionária, mas os testes de raiz unitária apontam para uma possivel não estacionariedade da taxa Selic. Em função disso, apresenta-se abaixo as funções de impulso resposta considerando a taxa Selic na 1a diferença. A ordem considerada foi a de Minella et al. (2003). Qualitativamente, as funções de impulso resposta possuem em geral o mesmo formato de anteriormente. A diferença é que em alguns casos o indicador de atividade considerado passa a se elevar após um breve período após uma alta da Selic.

Tabela A.1: Testes de raiz unitária — Philips Perron

\begin{tabular}{lc}
\hline Série & $\begin{array}{c}\text { P-valor da estatística do } \\
\text { teste }\end{array}$ \\
\hline IBC-BR & 0,0143 \\
Confiança do Consumidor & 0,0079 \\
Taxa de Desemprego & 0,0101 \\
Produção Industrial & 0,0122 \\
Vendas a Varejo & 0,0038 \\
CAGED & 0,3028 \\
Volatilidade do IBOVESPA & 0,0000 \\
Selic & 0,1403 \\
IPCAs & 0,0000 \\
Índice de incerteza & 0,0000 \\
Desvio-padrão das expectativas de crescimento 1 ano à frente & 0,0495 \\
Desvio-padrão das expectativas de crescimento 2 anos à frente & 0,0020 \\
Desvio-padrão das expectativas de crescimento 3 anos à frente & 0,2864 \\
\hline
\end{tabular}

\footnotetext{
${ }^{9}$ A exceção fica por conta da taxa Selic, em que os resultados apresentados abaixo foram efetuados na suposição de estacionariedade ao redor da tendência.
} 
Tabela A.2: Testes de raiz unitária — DFGLS

\begin{tabular}{|c|c|c|c|c|c|c|c|c|c|}
\hline Defasagens & IBC-BR & CONFI & DES & PI & VV & CAGED & IBOV & SELIC & IPCA \\
\hline 1 & $-2,175^{* *}$ & $-2,773^{* * *}$ & $-1,812^{*}$ & $-3,067^{* * *}$ & $-1,700$ & $-1,393$ & $-4,462^{* * *}$ & $-2,555$ & $-1,643$ \\
\hline 2 & $-2,436^{* *}$ & $-2,423^{* *}$ & $-1,694$ & $-3,070^{* * *}$ & $-1,329$ & $-2,386^{* *}$ & $-3,782^{* * *}$ & $-2,667$ & $-1,460$ \\
\hline 3 & $-2,487^{* *}$ & $-2,316^{* *}$ & $-1,680$ & $-3,265^{* * *}$ & $-1,178$ & $-2,497^{* * *}$ & $-3,636^{* * *}$ & $-2,659$ & $-1,399$ \\
\hline 4 & $-2,278^{* *}$ & $-2,596^{* *}$ & $-1,788^{*}$ & $-3,121^{* * *}$ & $-1,315$ & $-1,991^{*}$ & $-3,209^{* * *}$ & $-1,937$ & $-1,324$ \\
\hline 5 & $-2,380^{* *}$ & $-2,715^{* * *}$ & $-1,776^{*}$ & $-3,373^{* * *}$ & $-1,166$ & $-2,056^{* *}$ & $-3,029^{* * *}$ & $-1,673$ & $-1,316$ \\
\hline 6 & $-2,220^{* *}$ & $-2,510^{* *}$ & $-1,706$ & $-3,146^{* * *}$ & $-1,341$ & $-1,959^{*}$ & $-2,689^{* * *}$ & $-1,788$ & $-1,318$ \\
\hline 7 & $-2,224^{* *}$ & $-2,074^{* *}$ & $-1,772^{*}$ & $-3,146^{* * *}$ & $-1,320$ & $-1,635$ & $-2,403^{* *}$ & $-1,895$ & $-1,526$ \\
\hline 8 & $-2,309^{* *}$ & $-2,104^{* *}$ & $-1,815^{*}$ & $-3,410^{* * *}$ & $-1,365$ & $-1,609$ & $-2,349^{* *}$ & $-2,024$ & $-1,693$ \\
\hline 9 & $-1,892^{*}$ & $-1,962^{*}$ & $-2,054^{* *}$ & $-3,153^{* * *}$ & $-1,515$ & $-1,586$ & $-2,296^{* *}$ & $-1,511$ & $-1,784$ \\
\hline 10 & $-2,096^{* *}$ & $-1,798^{*}$ & $-2,041^{* *}$ & $-3,004^{* * *}$ & $-1,405$ & $-1,235$ & $-2,104^{* *}$ & $-1,230$ & $-1,850$ \\
\hline 11 & $-2,313^{* *}$ & $-1,740^{*}$ & $-2,083^{* *}$ & $-3,054^{* * *}$ & $-0,962$ & $-1,228$ & $-1,824^{*}$ & $-1,044$ & $-1,835$ \\
\hline 12 & $-2,278^{* *}$ & $-1,495$ & $-1,692^{*}$ & $-3,097^{* * *}$ & $-0,589$ & $-1,310$ & $-1,932^{*}$ & $-1,045$ & $-1,956$ \\
\hline \multirow[t]{2}{*}{ Critério } & \multicolumn{9}{|c|}{ Defasagem selecionada pelo critério } \\
\hline & IBC-BR & CONFI & DES & PI & VV & CAGED & IBOV & SELIC & IPCA \\
\hline Ng-Perron & 0 & 7 & 0 & 0 & 12 & 2 & 0 & 9 & 12 \\
\hline SIC & 1 & 1 & 1 & 1 & 1 & 2 & 1 & 1 & 1 \\
\hline MAIC & 1 & 2 & 1 & 1 & 2 & 4 & 11 & 11 & 8 \\
\hline
\end{tabular}

${ }^{*},{ }^{* *} \mathrm{e}^{* * *}$ indicam rejeção da hipótese nula a 10,5 e $1 \%$, respectivamente. 
Tabela A.3: Índice com a frequencia da palavra "incerteza" no caderno de economia dos jornais O Estado de São Pauo, Estado de Minas, Zero Hora e Correio Braziliense

\begin{tabular}{|c|c|c|c|c|c|}
\hline Período & Contagem & Índice normalizado & Período & Contagem & Índice normalizado \\
\hline $\mathrm{jan} / 04$ & 13 & $-0,36$ & $\mathrm{jan} / 07$ & 5 & $-1,33$ \\
\hline $\mathrm{fev} / 04$ & 17 & 0,12 & $\mathrm{fev} / 07$ & 11 & $-0,6$ \\
\hline $\mathrm{mar} / 04$ & 15 & $-0,12$ & $\mathrm{mar} / 07$ & 26 & 1,21 \\
\hline $\mathrm{abr} / 04$ & 23 & 0,85 & abr/07 & 7 & $-1,09$ \\
\hline mai/04 & 26 & 1,21 & $\mathrm{mai} / 07$ & 6 & $-1,21$ \\
\hline jun/04 & 27 & 1,33 & jun/07 & 8 & $-0,97$ \\
\hline jul/04 & 25 & 1,09 & jul/07 & 15 & $-0,12$ \\
\hline ago/04 & 23 & 0,85 & ago/07 & 29 & 1,57 \\
\hline set/04 & 18 & 0,24 & set/07 & 25 & 1,09 \\
\hline out/04 & 19 & 0,36 & out/07 & 9 & $-0,85$ \\
\hline nov/04 & 8 & $-0,97$ & nov/07 & 8 & $-0,97$ \\
\hline $\mathrm{dez} / 04$ & 15 & $-0,12$ & $\mathrm{dez} / 07$ & 25 & 1,09 \\
\hline $\mathrm{jan} / 05$ & 9 & $-0,85$ & jan/08 & 32 & 1,94 \\
\hline $\mathrm{fev} / 05$ & 3 & $-1,57$ & $\mathrm{fev} / 08$ & 16 & 0 \\
\hline $\mathrm{mar} / 05$ & 22 & 0,73 & $\mathrm{mar} / 08$ & 17 & 0,12 \\
\hline $\mathrm{abr} / 05$ & 10 & $-0,72$ & $\mathrm{abr} / 08$ & 18 & 0,24 \\
\hline mai/05 & 7 & $-1,09$ & $\mathrm{mai} / 08$ & 7 & $-1,09$ \\
\hline jun/05 & 26 & 1,21 & jun/08 & 8 & $-0,97$ \\
\hline jul/05 & 17 & 0,12 & jul/08 & 12 & $-0,48$ \\
\hline ago/05 & 26 & 1,21 & ago/08 & 21 & 0,61 \\
\hline set/05 & 28 & 1,45 & set/08 & 32 & 1,94 \\
\hline out/05 & 8 & $-0,97$ & out/08 & 60 & 5,32 \\
\hline nov/05 & 18 & 0,24 & nov/08 & 23 & 0,85 \\
\hline $\mathrm{dez} / 05$ & 18 & 0,24 & $\mathrm{dez} / 08$ & 25 & 1,09 \\
\hline $\mathrm{jan} / 06$ & 8 & $-0,97$ & jan/09 & 21 & 0,61 \\
\hline $\mathrm{fev} / 06$ & 6 & $-1,21$ & $\mathrm{fev} / 09$ & 16 & 0 \\
\hline $\mathrm{mar} / 06$ & 17 & 0,12 & $\mathrm{mar} / 09$ & 12 & $-0,48$ \\
\hline $\mathrm{abr} / 06$ & 19 & 0,36 & $\mathrm{abr} / 09$ & 13 & $-0,36$ \\
\hline $\mathrm{mai} / 06$ & 26 & 1,21 & $\mathrm{mai} / 09$ & 10 & $-0,72$ \\
\hline jun/06 & 19 & 0,36 & jun/09 & 18 & 0,24 \\
\hline jul/06 & 15 & $-0,12$ & jul/09 & 15 & $-0,12$ \\
\hline ago/06 & 9 & $-0,85$ & ago/09 & 5 & $-1,33$ \\
\hline set/06 & 19 & 0,36 & set/09 & 13 & $-0,36$ \\
\hline out/06 & 11 & $-0,6$ & out/09 & 7 & $-1,09$ \\
\hline nov/06 & 6 & $-1,21$ & nov/09 & 12 & $-0,48$ \\
\hline $\mathrm{dez} / 06$ & 4 & $-1,45$ & $\mathrm{dez} / 09$ & 17 & 0,12 \\
\hline
\end{tabular}


Tabela A.3: Índice com a frequencia da palavra "incerteza" no caderno de economia dos jornais O Estado de São Pauo, Estado de Minas, Zero Hora e Correio Braziliense (continuação)

\begin{tabular}{|c|c|c|c|c|c|}
\hline Período & Contagem & Índice normalizado & Período & Contagem & Índice normalizado \\
\hline $\mathrm{jan} / 10$ & 11 & $-0,6$ & $\mathrm{jan} / 13$ & 20 & 0,48 \\
\hline $\mathrm{fev} / 10$ & 15 & $-0,12$ & $\mathrm{fev} / 13$ & 22 & 0,73 \\
\hline $\operatorname{mar} / 10$ & 14 & $-0,24$ & $\operatorname{mar} / 13$ & 19 & 0,36 \\
\hline $\mathrm{abr} / 10$ & 9 & $-0,85$ & $\mathrm{abr} / 13$ & 10 & $-0,72$ \\
\hline $\mathrm{mai} / 10$ & 25 & 1,09 & mai/13 & 19 & 0,36 \\
\hline jun/10 & 17 & 0,12 & jun/13 & 31 & 1,81 \\
\hline jul/10 & 16 & 0 & $\mathrm{jul} / 13$ & 28 & 1,45 \\
\hline ago/10 & 17 & 0,12 & ago/13 & 23 & 0,85 \\
\hline set/10 & 8 & $-0,97$ & set/13 & 21 & 0,61 \\
\hline out/10 & 16 & 0 & out $/ 13$ & 17 & 0,12 \\
\hline nov/10 & 16 & 0 & nov/13 & 19 & 0,36 \\
\hline $\mathrm{dez} / 10$ & 8 & $-0,97$ & $\mathrm{dez} / 13$ & 29 & 1,57 \\
\hline $\mathrm{jan} / 11$ & 4 & $-1,45$ & & & \\
\hline $\mathrm{fev} / 11$ & 3 & $-1,57$ & & & \\
\hline $\operatorname{mar} / 11$ & 12 & $-0,48$ & & & \\
\hline abr/11 & 8 & $-0,97$ & & & \\
\hline mai/11 & 6 & $-1,21$ & & & \\
\hline jun/11 & 6 & $-1,21$ & & & \\
\hline jul/11 & 19 & 0,36 & & & \\
\hline ago/11 & 12 & $-0,48$ & & & \\
\hline set/11 & 16 & 0 & & & \\
\hline out/11 & 12 & $-0,48$ & & & \\
\hline nov/11 & 22 & 0,73 & & & \\
\hline $\mathrm{dez} / 11$ & 18 & 0,24 & & & \\
\hline $\mathrm{jan} / 12$ & 16 & 0 & & & \\
\hline $\mathrm{fev} / 12$ & 7 & $-1,09$ & & & \\
\hline mar/12 & 2 & $-1,69$ & & & \\
\hline abr/12 & 16 & 0 & & & \\
\hline $\mathrm{mai} / 12$ & 15 & $-0,12$ & & & \\
\hline jun/12 & 27 & 1,33 & & & \\
\hline jul/12 & 18 & 0,24 & & & \\
\hline ago/12 & 9 & $-0,85$ & & & \\
\hline set/12 & 17 & 0,12 & & & \\
\hline out $/ 12$ & 7 & $-1,09$ & & & \\
\hline nov/12 & 17 & 0,12 & & & \\
\hline $\mathrm{dez} / 12$ & 16 & 0 & & & \\
\hline
\end{tabular}

Tabela A.4: Períodos de maior incerteza pelo índice

\begin{tabular}{ll}
\hline Período & Motivo \\
\hline Mai04-Ju104 & Elevação de juros nos EUA. \\
Jun05-Ago05 & $\begin{array}{l}\text { Denúncias em relação a membros do governo (Palocci e Dirceu). } \\
\text { set/05 }\end{array}$ \\
Incertezas em relação ao preço do petróleo e crise política. \\
mai/06 & Elevação de juros nos EUA. \\
Mar07-Jan08 & Incertezas em relação à desaceleração da economia americana. \\
Set08-Out08 & Crise internacional. \\
dez/08 & Crise internacional, perspectiva de desaceleração da economia brasileira e desva- \\
& lorizção cambial. \\
mai/10 & Crise na Europa (situação fiscal da Grécia, Portugal e Espanha). \\
jun/12 & Crise na Europa (situação fiscal da Grécia, Portugal e Espanha). \\
Jun13-Jul13 & Manifestações populares, incerteza cambial \\
dez/13 & Incerteza em relação às perspectivas da economia brasileira e política monetária \\
& americana. \\
\hline
\end{tabular}




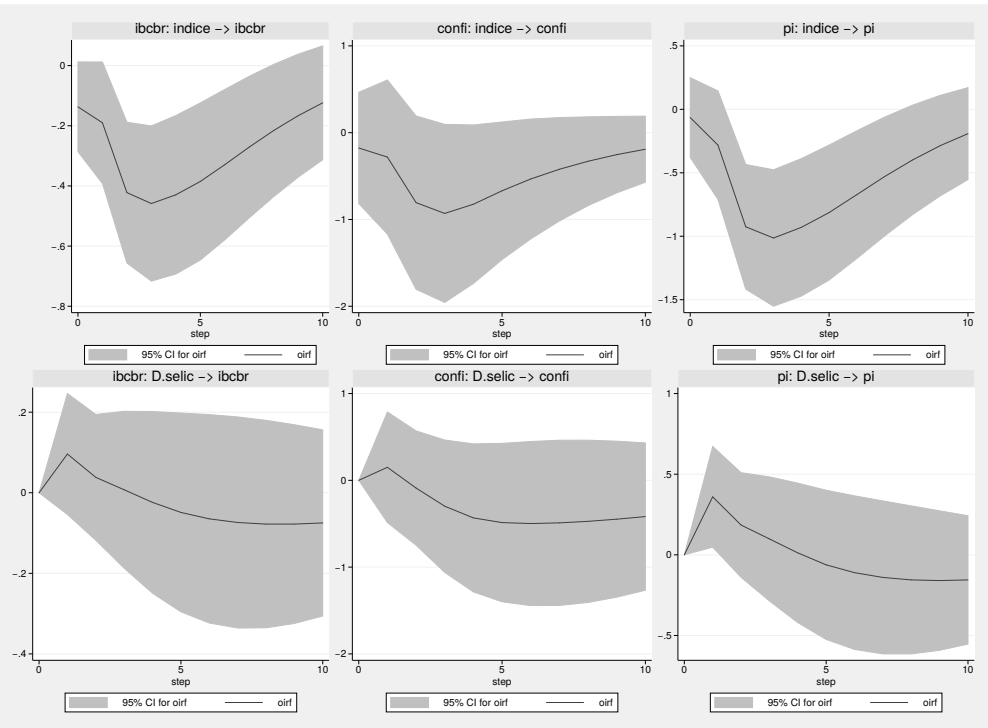

Figura A.1: VAR ampliado. Ordem: Índice, atividade, IPCA e Selic na 1a diferença

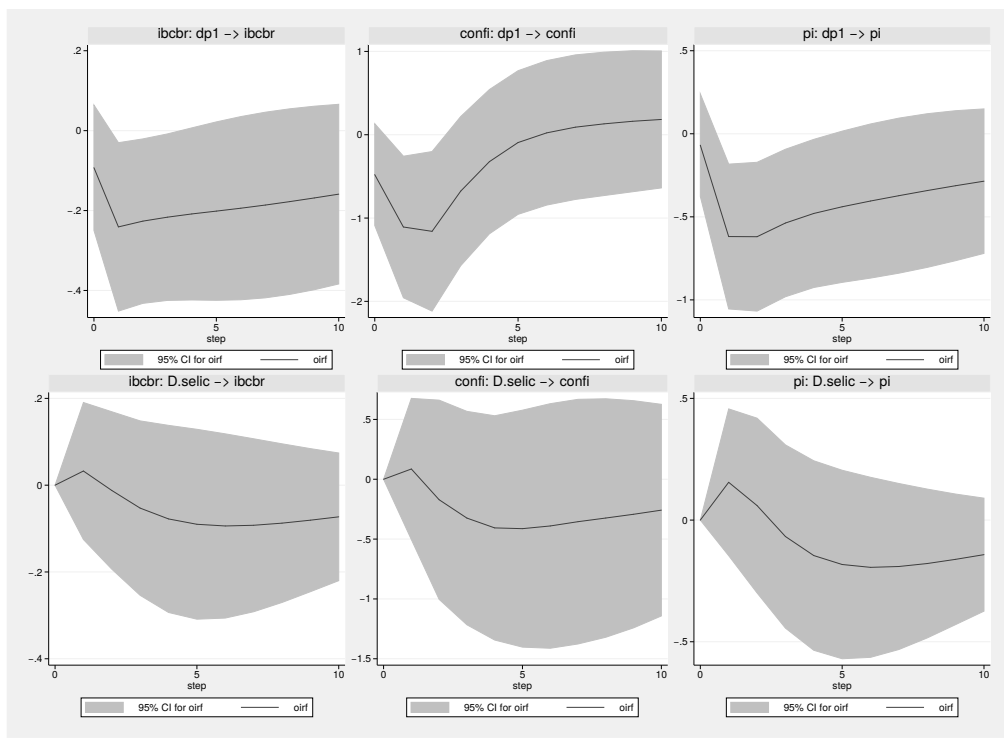

Figura A.2: VAR ampliado. Ordem: Desvio-padrão das expectativas de crescimento 1 ano à frente, atividade, IPCA e Selic na 1a diferença 


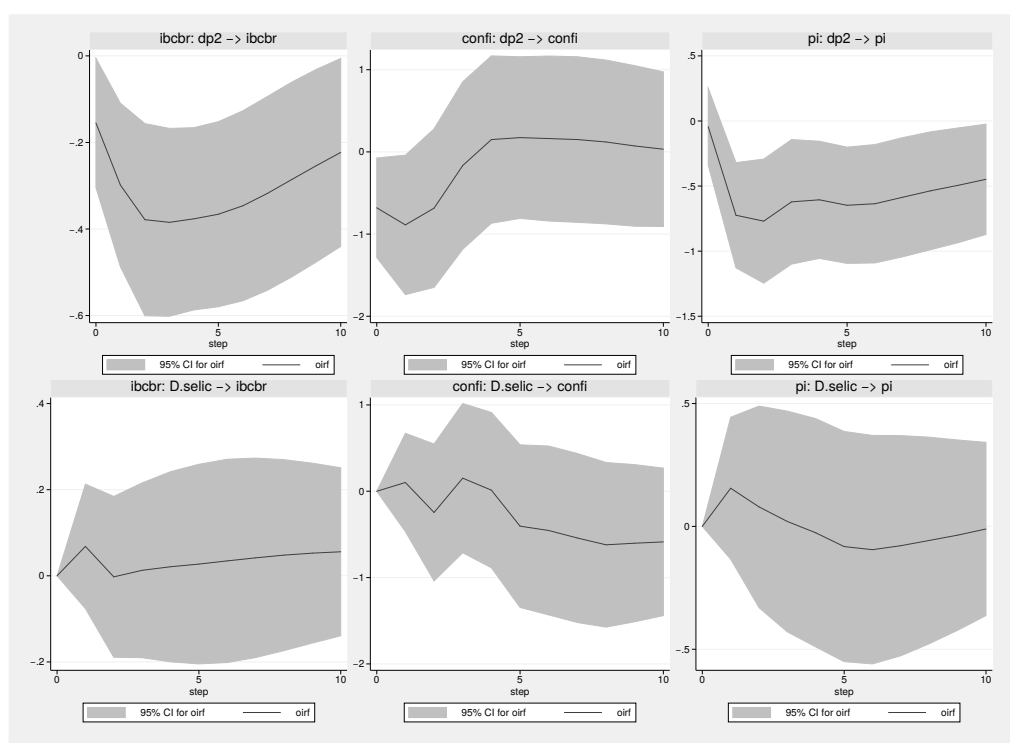

Figura A.3: VAR ampliado. Ordem: Desvio-padrão das expectativas de crescimento 2 anos à frente, atividade, IPCA e Selic na 1a diferença

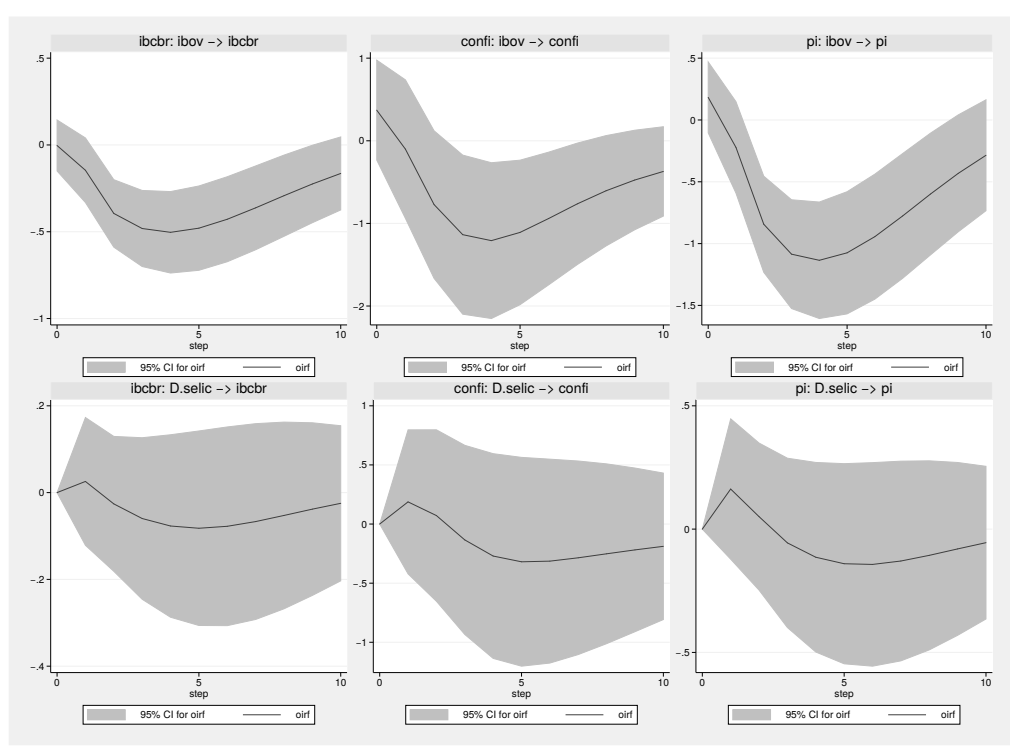

Figura A.4: VAR ampliado. Ordem: Volatilidade do IBOVESPA, atividade, IPCA e Selic na 1a diferença 